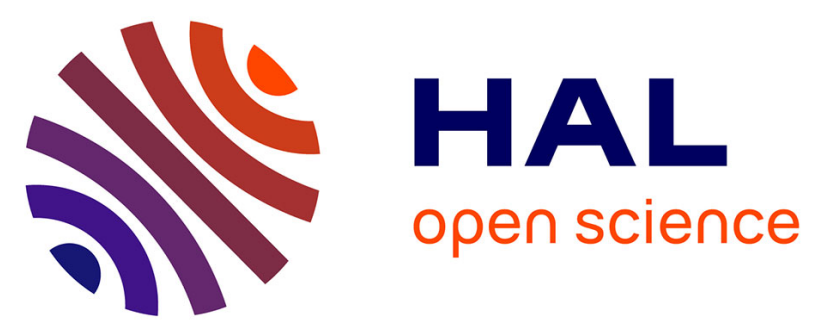

\title{
Evidence of an additional center of apple domestication in Iran, with contributions from the Caucasian crab apple Malus orientalis Running head: Apple domestication in the Caucasus
}

\author{
Hamid Bina, Hamed Yousefzadeh, Anthony Venon, Carine Remoué, Agnès \\ Rousselet, Matthieu Falque, Faramarzi Shadab, Chen Xilong, Jarkyn \\ Samanchina, David Gill, et al.
}

\section{- To cite this version:}

Hamid Bina, Hamed Yousefzadeh, Anthony Venon, Carine Remoué, Agnès Rousselet, et al.. Evidence of an additional center of apple domestication in Iran, with contributions from the Caucasian crab apple Malus orientalis Running head: Apple domestication in the Caucasus. 2021. hal-03365757

\author{
HAL Id: hal-03365757 \\ https://hal.science/hal-03365757
}

Preprint submitted on 5 Oct 2021

HAL is a multi-disciplinary open access archive for the deposit and dissemination of scientific research documents, whether they are published or not. The documents may come from teaching and research institutions in France or abroad, or from public or private research centers.
L'archive ouverte pluridisciplinaire HAL, est destinée au dépôt et à la diffusion de documents scientifiques de niveau recherche, publiés ou non, émanant des établissements d'enseignement et de recherche français ou étrangers, des laboratoires publics ou privés. 
1 Title: Evidence of an additional center of apple domestication in Iran, 2 with contributions from the Caucasian crab apple Malus orientalis

4 Running head: Apple domestication in the Caucasus

6 Bina Hamid ${ }^{1}$, Yousefzadeh Hamed ${ }^{2}$, Venon Anthony ${ }^{3}$, Remoué Carine ${ }^{3}$, Rousselet Agnès ${ }^{3}$,

7 Falque Matthieu ${ }^{3}$, Shadab Faramarzi ${ }^{4}$, Xilong Chen $^{3}$, Jarkyn Samanchina ${ }^{5}$, David Gill ${ }^{5}$, Akylai

8 Kabaeva $^{5}$, Giraud Tatiana ${ }^{6}$, Hossainpour Batool ${ }^{7}$, Abdollahi Hamid ${ }^{8}$, Gabrielyan Ivan',

9 Nersesyan Anush $^{10}$, Cornille Amandine ${ }^{3}$

$11{ }^{1}$ Department of Forestry, Tarbiat Modares University, Noor, Iran

$12{ }^{2}$ Department of Environmental science, Biodiversity Branch, Natural resources faculty, Tarbiat

13 Modares University, Noor, Iran

$14{ }^{3}$ Université Paris-Saclay, INRAE, CNRS, AgroParisTech, GQE - Le Moulon, 91190 Gif-sur-

15 Yvette, France

$16{ }^{4}$ Department of Plant Production and Genetics, Faculty of Agriculture, Razi University,

17 Kermanshah, Iran

$18 \quad{ }^{5}$ Fauna \& Flora International, Cambridge, UK

$19{ }^{6}$ Ecologie Systematique Evolution, Universite Paris-Saclay, CNRS, AgroParisTech, Orsay,

20 France

$21{ }^{7}$ Iranian Research Organization for Science and Technology (IROST), Institute of Agriculture,

22 Department of Agriculture, Tehran, Iran

$23{ }^{8}$ Temperate Fruits Research Center, Horticultural Sciences Research Institute, Agricultural

24 Research, Education and Extension Organization (AREEO), Karaj, Iran

$25{ }^{9}$ Department of Conservation of Genetic Resources of Armenian Flora, A. Takhtajyan Institute

26 of Botany, Armenian National Academy of Sciences, Acharyan Str.1, 0040 Yerevan, Armenia

$27{ }^{10}$ Department of Palaeobotany, A. Takhtajyan Institute of Botany, Armenian National Academy

28 of Sciences, Acharyan Str.1, 0040 Yerevan, Armenia

29

30 Corresponding authors: amandine.cornille@ universite-paris-saclay.fr,

31 hamed.yousefzadeh@modares.ir 
33 Key words: apple, Caucasus, crop-wild gene flow, domestication, fruit tree, climate, 34 introgression.

\section{Abstract}

36 Anthropogenic and natural divergence processes in crop-wild fruit tree complexes are less

37 studied than in annual crops, especially in the Caucasus, a pivotal region for plant domestication.

38 We investigated anthropogenic and natural divergence processes in apples in the Caucasus using

3926 microsatellite markers amplified in 550 wild and cultivated samples. We found two distinct

40 cultivated populations in Iran, that were both genetically differentiated from Malus domestica,

41 the standard cultivated apple worldwide. Coalescent-based inferences using approximate

42 Bayesian computation showed that these two cultivated populations originated from specific

43 domestication events in Iran. One of the Iranian clusters encompassed both cultivated and forest

44 trees, suggesting that either farmers use of local wild apple for cultivation or that some forest

45 trees represent feral cultivars. We found evidence of substantial wild-to-crop, crop-crop and crop-

46 to-wild gene flow in the Caucasus, as has been previously described in apple in Europe and in

47 fruit trees in general. In the Caucasus, we identified seven genetically differentiated populations

48 of wild apple (Malus orientalis). Niche modeling combined with genetic diversity estimates

49 indicated that these populations likely resulted from range changes during the last glaciation. This

50 study identifies Iran as a key region in the evolution and domestication of apple and further

51 demonstrates the role of wild-to-crop gene flow during fruit tree domestication. Our results

52 support the view that domestication of fruit trees was likely a geographically diffuse and

53 protracted process, involving multiple, geographically disparate, origins of domestication. We

54 also highlight the impact of climate change on the natural divergence of a wild fruit tree and

55 provides a base for apple conservation and breeding programs in the Caucasus. 


\section{Introduction}

61 Crop-wild complexes provide good models for understanding how anthropogenic and natural

62 factors shape population divergence in the presence of gene flow. Indeed, crops are the result of a

63 recent anthropogenic divergence process, i.e., domestication, which began around 10,000 years

64 ago, and which has often been followed by subsequent crop-wild gene flow (Besnard, Terral, \&

65 Cornille, 2018; Brandenburg et al., 2017; Chen et al., 2019; Cornille, Giraud, Smulders, Roldán-

66 Ruiz, \& Gladieux, 2014; Cornille et al., 2012; Diez et al., 2015; Flowers et al., 2019; Gaut, Díez,

$67 \&$ Morrell, 2015). Conversely, wild species allow the study of natural divergence over a longer

68 timescale. Indeed, wild species have often undergone shifts in their distribution following past

69 climate changes associated with glacial periods, and range contraction has often led to population

70 differentiation and divergence (Excoffier, Foll, \& Petit, 2009; Hewitt, 1990; Hewitt, 1996;

71 Jezkova, Olah-Hemmings, \& Riddle, 2011; Petit, Bialozyt, Garnier-Géré, \& Hampe, 2004;

72 Schmitt, 2007). Understanding the evolutionary processes shaping the natural and anthropogenic

73 divergence of crop-wild complexes is not just an academic exercise: it will also help assess the

74 future status of wild resources. Because of the socio-economic importance of crop plants,

75 protecting the wild relatives of crops, beyond the need for preserving biodiversity (Bacles \&

76 Jump, 2011), will allow us to manage the genetic resources for future breeding strategies in the

77 face of global changes (e.g., climate change, emerging diseases) (Bailey-Serres, Parker,

78 Ainsworth, Oldroyd, \& Schroeder, 2019; Castañeda-Álvarez et al., 2016; H. Zhang, Mittal,

79 Leamy, Barazani, \& Song, 2017).

$80 \quad$ Fruit trees present several historical and biological features that make them fascinating

81 models for investigating anthropogenic and natural divergence with gene flow. Several fruit tree

82 crops are spread across the world and are sometimes found in sympatry with their wild relatives

83 (Besnard et al., 2018; Cornille et al., 2019, 2014; Liu et al., 2019). Fruit trees are also

84 characterized by high levels of gene flow during divergence, which is to be expected considering

85 the typical life history traits of trees (Cornille et al., 2013; Cornille, Gladieux, \& Giraud, 2013a;

86 Oddou-Muratorio \& Klein, 2008; Petit \& Hampe, 2006). Population genetics studies of natural

87 divergence processes associated with the last glacial maximum in Europe, North America and

88 Asia in wind-dispersed trees (e.g., Abies, Pinus, Fraxinus, Quercus, Betula (Lascoux, Palmé,

89 Cheddadi, \& Latta, 2004; Petit et al., 2004)) and animal-dispersed trees (Cornille et al., 2013a)

90 showed that there were high levels of gene flow between populations and that trees had high 
91 dispersal capabilities. These studies also located single (Bai \& Spitkovsky, 2010; Tian, Li, Ji,

92 Zhang, \& Luo, 2009; Zeng et al., 2011) or multiple (Qiu, Wang, Liu, Shen, \& Tang, 2011; Tian

93 et al., 2009) glacial refugia where most temperate tree species persisted during the last glacial

94 maximum, and from which populations recolonized higher or lower latitudes during the Holocene

95 post-glacial expansion (Giesecke, Brewer, Finsinger, Leydet, \& Bradshaw, 2017). Population

96 genetics and genomics studies also revealed the prominent role of gene flow during the

97 anthropogenic divergence of fruit trees. Domestication of several emblematic fruit tree crops such

98 as grape and apple occurred with substantial crop-crop and wild-crop gene flow and without a

99 bottleneck (Arroyo-García et al., 2006; Cornille et al., 2012; Decroocq et al., 2016; Diez et al.,

100 2015; Duan et al., 2017; Liu et al., 2019; Meyer, Duval, \& Jensen, 2012; Myles et al., 2011).

101 These studies thus revealed that fruit tree domestication displays different patterns from those of

102 annuals, with for example milder bottlenecks, which can be explained by the long lifespan, long

103 juvenile phase and self-incompatibility system of trees (Fuller, 2018; Gaut et al., 2015).

104 However, studies of natural and anthropogenic divergence processes in crop-wild fruit tree

105 complexes are still scarce in the geographic regions that were pivotal in the divergence history of 106 these complexes.

107 The Caucasus ecoregion harbors a remarkable concentration of both economically 108 important plants and their wild relatives, in particular wheat, rye, barley and also fruit trees 109 including walnut, apricot and apple (Asanidze, Akhalkatsi, Henk, Richards, \& Volk, 2014a;

110 Gabrielian \& Zohary, 2004; Vavilov, 1926, 1992; Yousefzadeh, Hosseinzadeh Colagar, Tabari,

111 Sattarian, \& Assadi, 2012). This region covers Georgia, Armenia, Azerbaijan, the North

112 Caucasian part of the Russian Federation, the northeastern part of Turkey and the Hyrcanian

113 Mixed Forests region in northwestern Iran (Nakhutsrishvili, Zazanashvili, Batsatsashvili, \&

114 Montalvo, 2015; Zazanashvili et al., 2020). Two Pleistocene refugia for temperate plants are 115 recognized in this region (Bina, Yousefzadeh, Ali, \& Esmailpour, 2016; Yousefzadeh et al., 116 2012): the Colchis refugium in the catchment basin of the Black Sea (in the Western Caucasus), 117 and the Hyrcanian refugium at the southern edge of the Caspian Sea. Glacial refugia are known to 118 harbor higher levels of species and genetic diversity (Hewitt, 2004), and this is the case for the 119 Colchis and Hyrcanian refugia. The geography of the Caucasus, with two parallel mountain 120 chains separated by contrasted climatic zones, makes this region a good model for investigating 121 the natural divergence processes associated with the last glacial maximum. Furthermore, it has 
122 been suggested that Iran, with its close proximity to Central Asia - the center of origin of

123 emblematic fruit trees - and its historic position on the Silk Trade Routes, is a possible secondary

124 center of domestication of apple, grape and apricot (Decroocq et al., 2016; Liang et al., 2019; Liu

125 et al., 2019). However, inferences of the natural and anthropogenic divergence history of wild-

126 crop fruit tree complexes in the Caucasus have been limited by the small number of samples

127 (Decroocq et al., 2016; Liu et al., 2019) and/or genetic markers investigated so far

128 (Amirchakhmaghi et al., 2018; Asanidze, Akhalkatsi, Henk, Richards, \& Volk, 2014b; Cornille et

129 al., 2013a; Gharghani et al., 2010; Myles et al., 2011; Volk \& Cornille, 2019; Vouillamoz et al., 130 2006).

131 The Caucasian crab apple, Malus orientalis Uglitzk., is an endemic wild apple species 132 occurring in the Caucasus. More specifically, it is found in the Western Caucasus (i.e., the 133 southern part of Russia, northern Anatolia and northwestern Turkey), Georgia, Armenia, the 134 mountainous belt in northern Iran, the Hyrcanian Forests (Büttner, 2001; Rechinger, 1964) and 135 the Zagros forests in eastern and central Iran (Browicz, 1969; Rechinger, 1964) (Figure 1). This 136 species displays high phenotypic diversity across its distribution range where it occurs as 137 scattered individuals in natural forests or at high altitude in rocky mountains (Fischer \& Schmidt, 138 1938; Rechinger, 1964). It has a high resistance to pests and diseases (Büttner, 2001) and its fruit, 139 of high quality, are variable in size (2-4 cm) and color (green to yellowish) (Cornille et al., 2014). 140 Fruit of $M$. orientalis are harvested across the Caucasus for stewing and processed as juice and 141 other beverages (cider, wine), jelly, syrup, jam, and vinegar (Amirchakhmaghi et al., 2018; 142 Büttner, 2001). This has led some authors to suggest that some local apple cultivars from several 143 regions of the Caucasus originated from M. orientalis (Forsline, Aldwinckle, Dickson, Luby, \& 144 Hokanson, 2003; Langenfeld, 1991; Schmitt, 2007). Other studies also suggested that $M$. 145 orientalis has been present and cultivated in Iran long before the $M$. domestica trees were 146 introduced (Gharghani et al., 2009; Gharghani et al., 2010; Spengler, 2019). Malus domestica, the 147 standard cultivated apple, is also currently grown in various regions of the Caucasus (Forsline et 148 al., 2003; Gharghani et al., 2010; Gharghani et al., 2009; Langenfeld, 1991; Schmitt, 2007). So 149 far, the relationships between $M$. orientalis, the local Caucasian cultivars, $M$. domestica and its 150 Central Asian progenitor, Malus sieversii, are still unknown. This raises the following questions: 151 i) Are cultivated apples in the Caucasus derived from the same domestication event as $M$. 152 domestica? ii) If not, has $M$. orientalis contributed to the local cultivated Caucasian apple 
153 germplasm through wild-to-crop introgression, in the same way that $M$. sylvestris, the European crab apple, contributed to the $M$. domestica gene pool (Cornille et al., 2012; Ali Gharghani et al., 2009)?; iii) Are wild M. orientalis and/or crop-wild hybrid trees cultivated in gardens and orchards in Iran? Conversely, are there feral and/or hybrid trees in the wild? The extent of cropwild gene flow in apples in the Caucasus has just begun to be investigated. One study suggested that $M$. orientalis only made a minor contribution to Mediterranean $M$. domestica cultivars

159 (Cornille et al., 2012), but lacked in-depth investigation. A population genetics study revealed 160 low levels of crop-to-wild gene flow from M. domestica to M. orientalis in natural forests of Armenia, Turkey and Russia (Cornille et al., 2013a). Population genetic diversity and structure analyses of $M$. orientalis populations from the Western and South Caucasus identified three differentiated populations: one in Turkey, one in Armenia and one in Russia (Cornille et al., 2013a). On a smaller geographic scale, an east-west genetic subdivision was found across the Hyrcanian Forests in Iran, with five main populations showing admixture (Amirchakhmaghi et al., 2018). However, we still lack a comprehensive view (beyond Armenia) of the genetic diversity and structure of $M$. orientalis to understand its natural divergence history. In addition, studying local cultivars from the Caucasus will shed light on the relationships between local wild apple populations, the local cultivated apple and the standard cultivated apple M. domestica, as well as the extent of crop-wild gene flow in apple in this region.

Here, we investigate anthropogenic and natural divergence processes in apples from the

172 Caucasus and the extent of gene flow during divergence. A total of 550 apple trees, comprising 173 local cultivated and wild apples from the Caucasus, $M$. domestica apple cultivars and $M$. 174 sieversii, were sampled and genotyped using 26 microsatellite markers. In addition, the Siberian 175 wild apple Malus baccata was used as an outgroup in certain analyses. From the analysis of this 176 comprehensive genetic dataset, combined with ecological niche modeling approaches, we 177 addressed the following questions: 1) What is the population genetic structure among Caucasian 178 wild and cultivated apples, M. domestica and $M$. sieversii, and what are their genetic 179 relationships, levels of genetic diversity and demographic history? 2) Is there any crop-crop or 180 crop-wild gene flow in the Caucasus? Are there feral or crop-wild hybrid trees in the wild or, 181 conversely, do humans cultivate wild or hybrid trees? 3) Did M. orientalis experience past range 182 contraction and expansion associated with the last glacial maximum? 


\section{Materials and methods}

\section{Sampling, DNA extraction and microsatellite genotyping}

186 Microsatellite genotyping data for M. orientalis (Cornille et al., 2013a, 2012), M. sieversii from

187 Kazakhstan (Cornille et al., 2013a), M. domestica (Cornille et al., 2013a) and M. baccata

188 (Cornille et al., 2012) were from previously published studies; we had previously available data 189 for 207 M. orientalis individuals from Turkey, Armenia and Russia (23 sites, Tables S1 and S2), 190 four apple cultivars from Armenia, 40 "pure" European cultivated M. domestica individuals (i.e., 191 not -introgressed by M. sylvestris) (Tables S1 and S2), 20 M. sieversii individuals from 192 Kazakhstan (Cornille et al., 2012) and 22 M. baccata individuals from Russia (Cornille et al., 193 2012). We collected new samples in 2017 in Iran and in 2018 in Kyrgyzstan (M. sieversii). A 194 total of 257 samples were collected for this study: 167 M. orientalis individuals from the 195 Hyrcanian Forests and the Zagros region in Iran (Table S1), 48 local Iranian apple cultivars from the Seed and Plant Improvement Institute (Karaj, Iran) (Table S1) and 42 M. sieversii individuals from Kyrgyzstan. Note that for 18 of the 48 local Iranian samples, we measured fruit size (Table $\mathrm{S} 1)$. Collections meet the requirements of the recently enacted Nagoya protocol on access to genetic resources and the fair and equitable sharing of benefits. Thus, a total of 550 individuals were analyzed, comprising 374 wild M. orientalis, 48 Iranian and four Armenian apple cultivars, 40 European apple cultivars belonging to $M$. domestica, 62 M. sieversii (from Kyrgyzstan and Kazakhstan) and 22 M. baccata individuals (details are provided in Table S1).

DNA from the new samples $(N=257)$ was extracted from dried leaves with the NucleoSpin plant II DNA extraction kit (Macherey \& Nagel, Düren, Germany®) following the manufacturer's instructions. Multiplex microsatellite PCR amplifications were performed with a multiplex PCR kit (Qiagen Inc. $®$ ) for 26 microsatellite markers as previously described (Cornille et al., 2012; Patocchi, Frei, Frey, \& Kellerhals, 2009). Note that on each DNA plate, we included three controls, i.e., one sample of M. orientalis, one of $M$. sieversii and one of M. domestica for which data were already available (Cornille et al., 2013a). Genotypes of the controls for each of the 26 microsatellite markers were compared with the 2013 dataset. We retained only multilocus

212 population genetics analyses has been demonstrated in previous studies (Cornille et al., 2013a;

213 Cornille, Gladieux, \& Giraud, 2013b; Cornille et al., 2012). 
215 Bayesian inferences of population structure and genetic differentiation among wild and 216 cultivated apples

217 We investigated the population structure of wild and cultivated apples with the individual-based 218 Bayesian clustering methods implemented in STRUCTURE 2.3.3 (Pritchard, Stephens, \& 219 Donnelly, 2000). STRUCTURE uses Markov chain Monte Carlo (MCMC) simulations to infer 220 the proportion of ancestry of genotypes from $K$ distinct clusters. The underlying algorithms 221 attempt to minimize deviations from Hardy-Weinberg within clusters and linkage disequilibrium 222 among loci. We ran STRUCTURE from $K=1$ to $K=15$. Based on 10 repeated runs of MCMC 223 sampling from 500,000 iterations after a burn-in of 50,000 steps, we determined the amount of 224 additional information explained by increasing $K$ using the $\Delta K$ statistic (Evanno, Regnaut, \& 225 Goudet, 2005) as implemented in the online post-processing software Structure Harvester (Earl, 226 2012). However, the $K$ value identified with the $\Delta K$ statistic often does not correspond to the most biologically relevant number of clusters, as it only corresponds to the strongest population

228 subdivision level and not the finest subdivision level (Puechmaille, 2016); we therefore visually 229 checked the bar plots and chose the $K$ value for which all clusters had well-assigned individuals 230 (indicating the existence of a genuine population subdivision), while no further well-delimited 231 and biogeographically relevant clusters could be identified for higher $K$ values (indicating we 232 reached the highest $K$ value for which new genuine clusters could be delimited).

233 We ran STRUCTURE for the whole dataset $(N=550)$ to investigate the population 234 genetic structure among the Caucasian wild apple $M$. orientalis, the Caucasian cultivated apples, $235 M$. sieversii, $M$. domestica and $M$. baccata. We further explored the genetic variation and 236 differentiation among the genetic groups detected with STRUCTURE using three different 237 methods. First, we ran a principal component analysis (PCA) for all individuals with the dudi.pca 238 function from the adegenet $\mathrm{R}$ package (Jombart \& Ahmed, 2011). For the PCA, individuals that 239 were assigned to a given cluster with a membership coefficient $\geq 0.85$ were colored according to 240 the respective color of each cluster, and admixed individuals (i.e., individuals with a membership 241 coefficient to any given cluster $<0.85)$ were colored in gray. We chose this threshold based on 242 the distribution of the maximum membership coefficients inferred with STRUCTURE (see 243 results). The angle used to draw the PCA was 380 degrees for a better visualization of the data. 244 Second, we generated a neighbor-net tree with Splitstree v4 (Huson, 1998; Huson \& 245 Scornavacca, 2012), using the PCA color code. Third, we explored the relationships among 
246 populations identified with STRUCTURE (i.e., clusters of individuals with a membership 247 coefficient $\geq 0.85$ to a given cluster) with a neighbor joining (NJ) tree (Huson, 1998; Huson \& 248 Scornavacca, 2012). The NJ tree and the neighbor-net tree were built using Nei's standard 249 genetic distance (Nei, 1987) computed among individuals or populations with the Populations 250 software v1.2.31 (https://bioinformatics.org/populations/).

252 Genetic diversity estimates and test for the occurrence of a bottleneck in wild and cultivated 253 apples

254 We computed descriptive population genetic estimates for each population (i.e., each cluster 255 inferred with STRUCTURE, excluding admixed individuals with a membership coefficient < 256 0.85). We calculated allelic richness $\left(A_{R}\right)$ and private allelic richness $\left(A_{P}\right)$ with ADZE (Szpiech, 257 Jakobsson, \& Rosenberg, 2008) using standardized sample sizes of $N_{A D Z E}=7$ (one individual x 258 two chromosomes), corresponding to the minimal number of observations across populations. 259 Heterozygosity (expected and observed), Weir and Cockerham $F$-statistics and deviations from 260 Hardy-Weinberg equilibrium were calculated with Genepop v4.2 (Raymond \& Rousset, 1995; 261 Rousset, 2008).

\section{Approximate Bayesian computation to reconstruct the domestication history of the Iranian} cultivated apple

265 We used approximate Bayesian computation to test whether cultivated apples in the Caucasus were derived from the same domestication event as $M$. domestica. We used the newly developed $\mathrm{ABC}$ method based on a machine learning tool named "random forest" (ABC-RF) to perform model selection and parameter estimates (Estoup et al., 2018; Pudlo et al., 2016; Raynal et al., 2019). In brief, this method creates a "forest" of bootstrapped decision trees that ranks scenarios based on the summary statistics of the datasets. Some simulations are not used to build the trees and can thus be used to cross-validate the analysis by computing a "prior error rate". This

272 approach allows the comparison of complex demographic models (Pudlo et al., 2016) by 273 comparing groups of scenarios with a specific type of evolutionary event with other groups with 274 different types of evolutionary events instead of considering all scenarios separately (Estoup et 275 al., 2018). 
Using the ABC-RF framework, we compared different scenarios of domestication of Iranian cultivars, i.e., with an origin from i) M. domestica, ii) M. sieversii from Kazakhstan, iii) 278 another, unknown ancestor. Populations were defined as the clusters detected with STRUCTURE, removing putative hybrid individuals (i.e., individuals with a membership coefficient $<0.85$ to any given cluster). We removed putative hybrids in order to retrace the divergence history and historical gene flow among populations; more recent admixture events being detectable directly from the STRUCTURE bar plots. We assumed bidirectional gene flow among wild and cultivated apple populations. The model parameters used were: the divergence time between $X$ and $Y$ populations $\left(T_{X-Y}\right)$, the effective population size of population $X\left(N_{E-X}\right)$ and the migration rate per generation between $X$ and $Y$ populations $\left(m_{X-Y}\right)$. Prior values for divergence time were drawn from the log-uniform distribution bounded between the distributions used in the approximate Bayesian computations and are given in Table S3.

For all models, microsatellite datasets were simulated for 14 out of the 26 markers that had perfect repeats (Ch01h01, Ch01h10, Ch02c06, Ch02d08, Ch05f06, Ch01f02, Hi02c07, Ch02c09, Ch03d07, Ch04c07, Ch02b03b, MS06g03, Ch04e03, Ch02g01, (Cornille et al., 2013; Cornille et al., 2012; Patocchi, Fernàndez-Fernàndez, et al., 2009). We checked that the population structure inferred with 14 microsatellite markers did not differ significantly from the inferences obtained with 26 SSR markers (data not shown). We assumed a generalized stepwise model of microsatellite evolution. Mutation rates were allowed to vary across loci, with locusspecific mutation rates drawn from a gamma distribution $(\alpha, \alpha / \mu)$ where $\mu$ is the mutation rate per generation and $\alpha$ is a shape parameter. We assumed a log-uniform prior distribution for $\mu$ (1e-5, 1e-3) and a uniform distribution for $\alpha$ (1.30) (Table S3).

We used ABCtoolbox (Wegmann, Leuenberger, Neuenschwander, \& Excoffier, 2010) with fastsimcoal 2.5 (Excoffier \& Foll, 2011) to simulate datasets, using model parameters drawn from prior distributions (Table S3). We performed 7,500 simulations per scenario. For each simulation, we calculated three summary statistics per population with arlsumstats $\mathrm{v} 3.5$ (Excoffier and Lischer 2010): $H$, the mean heterozygosity across loci, $s d(G W)$, the standard deviation of the mean Garza-Williamson statistic over populations (Garza and Williamson, 2001) and the pairwise $F_{S T}$ between populations (Weir and Cockerham, 1984).

We used the abcrf v.1.7.0 R statistical package (Pudlo et al., 2016) to carry out the $\mathrm{ABC}-\mathrm{RF}$ analysis. This analysis provides a classification vote that represents the number of times 
307 a scenario is selected as the best one among $n$ trees in the constructed random forest. For each

308 ABC step, we selected the scenario, or the group of scenarios, with the highest number of classification votes as the best scenario, or best group of scenarios, among a total of 500

310 classification trees (Breiman, 2001). We computed the posterior probabilities and prior error rates

311 (i.e., the probability of choosing a wrong group of scenarios when drawing model index and 312 parameter values from the priors of the best scenario) over 10 replicate analyses (Estoup et al., 313 2018) for each $A B C$ step. We also checked visually that the simulated models were compatible 314 with the observed dataset by projecting the simulated and the observed datasets onto the two first 315 linear discriminant analysis (LDA) axes (Pudlo et al., 2016), and by checking that the observed 316 dataset fell within the clouds of simulated datasets. We then calculated parameter inferences 317 using the final selected model. Note that the ABC-RF approach includes the model checking step 318 that was performed a posteriori in previous $\mathrm{ABC}$ methods.

Identification of crop-wild hybrids and historical gene flow in the wild apple $M$. orientalis in the Caucasus

322 To assess the extent of crop-wild gene flow in the Caucasus, we removed $M$. sieversii and $M$. 323 baccata from the dataset (resulting in a dataset with $N=466$, Table S2) and ran STRUCTURE 324 with the same parameters as above. We defined hybrids resulting from crop-to-wild introgression 325 as $M$. orientalis trees assigned to the $M$. domestica or the Iranian or Armenian cultivated gene 326 pools with a membership coefficient $>0.10$. We defined hybrids resulting from wild-to-crop 327 introgression as cultivars assigned to any of the wild gene pools with a membership coefficient > 328 0.10. We chose this threshold based on the distribution of the maximum membership coefficients 329 inferred with STRUCTURE (see results).

330 After removing crop-wild hybrids, we estimated the extent of historical gene flow in $M$. 331 orientalis in the Caucasus using two methods. First, we tested whether there was a significant 332 isolation-by-distance (IBD) pattern. We computed the correlation between $F_{S T} /\left(1-F_{S T}\right)$ and the 333 natural algorithm of geographic distance with SPAGeDI 1.5 (Hardy \& Vekemans, 2002). Second, 334 for each population, we computed the Nason's kinship coefficient $F_{i j}$ between pairs of individuals $335 i$ and $j$ (Loiselle, Sork, Nason, \& Graham, 1995)) with SPAGeDI 1.5 (Hardy \& Vekemans, 2002), 336 and regressed $F_{i j}$ against the natural logarithm of geographic distance, $\ln \left(d_{i j}\right)$, to obtain the 337 regression slope $b$. We permuted the spatial position of individuals 9,999 times to test whether 
338 there was a significant spatial genetic structure between sites. We then calculated the $S p$ statistic,

339 defined as $S p=-b L d /\left(1-F_{N}\right)$, where $F_{N}$ is the mean $F_{i j}$ between neighboring individuals

340 (Vekemans \& Hardy, 2004a), and $-b L d$ is the regression slope of $F_{i j}$ against $\ln \left(d_{i j}\right)$. A low $S p$

341 implies low spatial population structure, which suggests high historical gene flow and/or high

342 effective population size.

\section{Spatial pattern of genetic diversity in the Caucasian crab apple}

345 We investigated spatial patterns of diversity in "pure" M. orientalis. To this aim, we excluded the 346 crop-to-wild hybrids detected in the second STRUCTURE analysis (i.e., excluding M. baccata 347 and $M$. sieversii), as well as $M$. domestica and the Iranian and Armenian cultivars. Spatial 348 patterns of genetic diversity in the "pure" M. orientalis were visualized by mapping the variation 349 across space $\left(A_{R}\right)$ at 36 sites (i.e., geographic locations for which at least five individuals were 350 successfully genotyped for each marker, Table S2) with the geometry-based inverse distance 351 weighted interpolation in QGIS (Quantum GIS, GRASS, SAGA GIS). We calculated allelic 352 richness $\left(A_{R}\right)$ and private allelic richness $\left(A_{P}\right)$ per site with ADZE (Szpiech et al., 2008) using 353 standardized sample sizes of $N_{A D Z E}=6$ (one individual x two chromosomes), corresponding to 354 the minimal number of observations across sites.

\section{Species distribution modeling}

357 The BIOMOD2 R package (Thuiller, Georges, Engler \& Breiner, 2016) was used to project past 358 and present distributions of $M$. orientalis following the species distribution modeling methods of 359 Leroy et al. (2014). A set of 19 bioclimatic variables from WorldClim.org was used in addition to 360 monthly temperature and precipitation values. Climate data were obtained for past conditions 361 from the last glacial maximum and for the current period between 1960 and 1990. The climate 362 projection at the 2.5-minute spatial resolution from the CCSM4 global climate model was used 363 (https://www.worldclim.org/data/worldclim21.html\#), as we previously showed that it was the 364 most accurate for apple trees (Cornille et al., 2013). Past and present distributions were projected 365 using three modeling algorithms: a generalized linear model (GLM), a generalized additive model (GAM) and artificial neural networks (ANN).

The location of 339 "pure" M. orientalis trees (i.e., individuals assigned to a wild apple 368 gene pool with a membership coefficient $>0.9$, see results from the second STRUCTURE 
analysis) provided the longitude and latitude coordinates. Duplicate data points were removed, resulting in 57 presence points for $M$. orientalis (Table S4). We did not have absence data so we randomly selected pseudo-absences to serve as "absence" points for the model, and weighted

372 presence and absence points equally as per Barbet-Massin et al. (2012). Models were calibrated using the set of bioclimatic variables and model evaluation was calculated with Jaccard's indices. Ensemble model forecasting was completed by pulling the average trend of the three modeling algorithms and retaining only the uncorrelated bioclimatic variables with a Pearson correlation threshold greater than 0.75 (Table S5). The model was run again using only variables with high predictive power.

\section{Results}

\section{Clear genetic structure and variation in cultivated and wild apples}

382 The $\Delta K$ statistic indicated that the strongest level of population subdivision was at $K=3$ (Figure

383 S1 a, b). However, further genetic subdivisions were observed for $K>3$, with well delimited and 384 biologically meaningful clusters. We therefore visually examined the bar plots and chose the $K$ 385 value at which all clusters had fully assigned individuals, indicating the finest level of genetic 386 subdivision. At $K=12$, STRUCTURE identified twelve well-delimited clusters (Figures 1 a, b and S2) corresponding to species and/or geographic regions (Figure 1). We therefore considered these twelve clusters as the most relevant genetic structure.

Among these twelve clusters were two distinct genetic clusters of $M$. sieversii, one from Kazakhstan and one from Kyrgyzstan (in two shades of light blue, respectively, Figure 1), and a specific genetic cluster of $M$. baccata (orange red). We identified seven distinct genetic groups of M. orientalis: a genetic group from the Western Caucasus (Russia, Turkey and northwestern Armenia; orange), a central Armenian group (blue), a southern Armenian group (brown), and

394 four genetic groups in Iran corresponding to two gene pools spread across the Zagros Forests 395 (including samples from the Lorestan province in light green and from the Kurdestan province in red), and two gene pools (pink and purple) spread across the Hyrcanian Forests (Figure $1 \mathrm{a}, \mathrm{b}$ ).

The $M$. domestica apple cultivars formed a specific genetic group (yellow) that was well

398 separated from the wild M. orientalis and the Iranian and Armenian cultivars. The Iranian apple

399 cultivars formed two gene pools: one that included only cultivars (dark green), and another 
400 (purple) that included cultivated trees and wild $M$. orientalis individuals from the Hyrcanian

401 Forests. We also detected Iranian cultivated trees that were highly admixed between the Iranian 402 cultivated dark green cluster, the Iranian purple cluster, the $M$. domestica yellow cluster and with 403 two other clusters (red and orange), the latter two included several wild $M$. orientalis individuals

404 from the Zagros Forests in the Kurdestan province in Iran and the Western Caucasus, respectively 405 (Figures 1 and S2). The four Armenian cultivated apple fell within the blue and orange clusters, 406 which also included wild M. orientalis trees.

407 We assigned individuals with a membership coefficient $>0.85$ to a given cluster to the 408 corresponding population (Figure S3) to assess the genetic variation among wild and cultivated 409 apples. The PCA (Figure 1c) showed that M. baccata was highly differentiated from the other 410 genetic groups (Figure 1c, upper left). The European (yellow) and the two Iranian cultivated 411 genetic clusters (green and purple) formed well differentiated gene pools (Figure 1c, lower right).

412 Malus orientalis from the Western Caucasus (orange) and Central and Southern Armenia (brown 413 and blue) were closer to each other than to the Iranian wild apples (light green, red and pink), 414 which clustered together. Malus sieversii from Kazakhstan was closer to the Armenian and 415 Iranian wild apple than $M$. sieversii from Kyrgyzstan.

416 STRUCTURE analysis and PCA thus revealed three main aspects in the history of 417 apples in the Caucasus. First, cultivated apples in Iran (dark green) may have resulted from a 418 domestication event that was independent from the domestication of $M$. domestica, as their 419 respective clusters are not closely related in the PCA. The close genetic relationships between the 420 wild and cultivated Iranian clusters indicates that the cultivated apples in Iran could have been 421 domesticated from the local wild apple, M. orientalis, although they could also be derived from $422 M$. sieversii or $M$. domestica with subsequent local gene flow in Iran. Second, the full 423 membership of a substantial number of cultivated trees to genetic clusters of wild M. orientalis 424 suggests that wild trees are grown in orchards for consumption without any strong domestication 425 process and/or feral individuals occur (e.g., the purple genetic cluster may represent a cultivated 426 group that is also found in the wild as feral). In addition, the high level of admixture in several 427 Iranian cultivated apple trees with wild $M$. orientalis gene pools indicate substantial wild-crop 428 gene flow. Third, the spatial population structure of $M$. orientalis in the Caucasus may result 429 from past range contraction and expansion associated with the last glacial maximum. We tested 430 these hypotheses as described in the methods. First, we investigated the genetic diversity, genetic 
431 differentiation and evolutionary history of cultivated and wild apple populations using a

432 statistical framework for assessing the probability of different domestication scenarios. Second,

433 we estimated the extent of crop-wild and wild-wild gene flow in apples in the Caucasus. Third,

434 we investigated past contraction and expansion of wild apple populations in the Caucasus using

435 both genetic diversity estimates and ecological niche modeling.

437 Genetic diversity and differentiation among wild and cultivated apples

438 The neighbor-net tree (Figure 2a) and the NJ tree (Figure 2b) confirmed that the apple cultivars

439 (M. domestica and the purple and dark green Iranian cultivar clusters) were distinct from the wild 440 populations (with the exception of the wild Hyrcanian purple group, see below). Note that we 441 excluded admixed individuals (i.e., individuals assigned with a membership coefficient $<0.85$ to 442 a given cluster) from the NJ analysis to better assess the genetic relationships among pure 443 cultivated and wild populations.

444 Individuals of $M$. domestica and M. sieversii from Kazakhstan were intermingled 445 (Figure 2a) and the genetic clusters of these species were sister groups (Figure 2b). Neither of the 446 two distinct Iranian cultivated gene pools (green and purple) was not sister groups with $M$. 447 domestica, supporting the view that specific domestication events have occurred in Iran. The two 448 cultivated apple populations from Iran were genetically highly differentiated (Table S6), were 449 sister groups (Figure 2) and had lower levels of genetic diversity and fewer private alleles than $M$. 450 domestica $(P<0.01$, Tables 1 and S7), with the purple gene pool displaying the lowest level of 451 genetic diversity and the least number of private alleles. The close relationships between trees 452 sampled in the Hyrcanian Forests and cultivars from the purple gene pool (Figures 1 and 2), and 453 the lower levels of genetic diversity in both of these populations suggest that the trees sampled in 454 the Hyrcanian Forests assigned to the purple genetic group may be feral. Alternatively, it may be 455 that the cultivated trees from the purple gene pool represent the first step of apple domestication 456 in Iran, i.e., wild trees cultivated by humans.

$457 \quad$ Malus orientalis and $M$. sieversii did not form a monophyletic group (Figure 2b). Wild 458 M. orientalis populations from the Western Caucasus, (orange) and from central (blue) and 459 southern (brown) Armenia grouped together, the latter two being sister groups. The M. orientalis 460 population from the Lorestan province (Iran; light green) was intermingled with the M. sieversii 461 population from Kyrgyzstan (cyan), (Figure 2a); when considered as separate populations (i.e., 
462 excluding admixed individuals Figure 2b), the two populations formed sister groups (Figure 2b).

463 Although the wild Hyrcanian (pink and purple) populations were intermingled (with the 464 exception of a few wild purple individuals clustering with the cultivated purple population) in the 465 neighbor-net tree, the NJ tree indicated that the wild purple population was closer to the 466 cultivated purple population. Some $M$. sieversii trees from Kazakhstan were intermingled with $M$. 467 sieversii from Kyrgyzstan and clustered with the wild Iranian populations. Malus sieversii from 468 Kazakhstan formed a distinct group, placed as a sister group to $M$. domestica in both neighbor-net 469 and NJ trees (Figure 2). The level of allelic richness was significantly lower in the wild apple 470 populations from the Zagros Forest (i.e., Lorestan (light green) and Kurdestan (red) than in the 471 other wild populations (Tables 1 and S7).

\section{Additional domestication events in Iran inferred with ABC-RF}

475 We defined the populations used in the ABC framework from the clusters detected with 476 STRUCTURE at $K=12$ for 550 wild and cultivated apple accessions, excluding admixed 477 individuals (i.e., with a membership coefficient $<0.85$ to any given cluster, Figure S2, as recent 478 gene flow can easily be seen from visual inspection of the barplots). We excluded the Armenian 479 cultivars as they were represented by only four individuals; we also excluded M. baccata and all 480 wild Iranian and Armenian populations to avoid intractably complex scenarios with too many 481 populations. We therefore included only $M$. sieversii from Kazakhstan, the cultivated (green) and 482 wild + cultivated (purple) populations from Iran.

483 We used a two-step nested ABC-RF approach. In the first step we inferred i) the sequence 484 of divergence of the purple wild and cultivated populations (ABC step 1, Figure 3), including 485 scenarios assuming a sister relationship between the cultivated and wild populations, which 486 would support that either the wild trees from the purple group are feral or that the cultivated trees 487 from the purple group represent an early domestication step of a wild genetic cluster. In the next 488 step, we inferred ii) the progenitor of the Iranian cultivated apple, i.e., either M. sieversii, M. 489 domestica or an unknown ancestral population (ABC step 2, Figure 3). To build the scenarios, we 490 assumed that the purple Iranian cultivated population was younger than the green Iranian 491 cultivated population, as the former population had a lower number of private alleles and lower 492 genetic diversity (Table 1). For all scenarios, we assumed bidirectional gene flow among 
493 populations. This nested $\mathrm{ABC}$ approach avoids comparing overly complex models with too many

494 populations and parameters, and is more powerful than testing all scenarios individually to

495 disentangle the main evolutionary events characterizing demography and divergence (Estoup et 496 al., 2018).

497 For each step of the ABC-RF approach, the projection of the reference table and the observed datasets onto the two LDA axes that explained most of the variance of the summary statistics showed that the observed data fell within the distribution of the simulated summary

500 statistics (Figure S4), forming distinct clouds for each scenario or groups of scenarios. Visual

501 inspection of the LDA plots indicated this method had a high power to discriminate and select

502 scenarios; results were subsequently validated by the ABC-RF inferences presented below.

$503 \quad$ For all ten replicates, the step 1 of the ABC-RF method supported the sister group status 504 of the cultivated and wild purple populations, indicating that either this wild population is feral or 505 that this cultivated group represents an early domestication step without strong genetic 506 differentiation (scenarios sc1-after, sc2-after, sc3-after, sc4-after, average of 298 votes out of the 507500 RF-trees; posterior probabilities $=58 \%$, prior error rate $=38.31 \%$, Figure 3, Table S8). Using 508 the group of scenarios selected in step 1 (Figure 3) as a backbone, all ten replicates of the second 509 step of the ABC-RF analyses provided support for the domestication of the purple and the green 510 Iranian cultivated apples from an unknown ancestral population (scenario sc1-feral, an average of 511308 votes out of the 500 RF-trees; posterior probabilities $=64.8 \%$, prior error rate $=8.5 \%$, 512 Figure 3, Table S9). ABC-RF inferences provided support for the independent domestication of 513 the two cultivated Iranian populations: i.e., the dark green and purple cultivated apple populations 514 diverged independently from an unknown ancestral population c. 2,190 years ago (ya) and 2,890 515 ya, respectively, while $M$. domestica diverged from $M$. sieversii c. 3,550 ya (Table S10).

517 Substantial crop-wild, crop-crop and wild-wild gene flow in apples in the Caucasus

518 The second STRUCTURE analysis, focusing on the Caucasus, revealed the same genetic 519 clustering for wild apples and $M$. domestica at $K=9$ (Figure S5) as in the previous analysis $(K=$ 520 12) (Figures 1 and 2). At $K=9$, 150 apple genotypes could be considered hybrids (i.e., 521 individuals assigned to a gene pool with a membership coefficient $<0.9$, this cut-off being 522 chosen on the basis of the distribution of the cumulated membership coefficients for each 523 individual at $K=9$, Figure S6); these 150 hybrids represented $32 \%$ of the total dataset (Table 2). 
524 The Iranian cultivars had the highest proportion of hybrids (67\%), mostly admixed with the wild 525 and cultivated gene pools from Iran, but also with the M. domestica gene pool. Hybrids of the 526 wild Armenian apple were mostly an admixture of the wild Armenian gene pools (i.e., Western, 527 Central and Southern), suggesting local gene flow between crop and wild populations.

528 We removed the 150 hybrids and all apple cultivars (Tables 2 and S2) and focused on 529 the extent of gene flow in the "pure" Caucasian wild apple M. orientalis. We detected a 530 significant but weak isolation by distance pattern across the Caucasus $(P<0.001, R$-squared $=$ 531 0.07, Figure S7), suggesting a high level of gene flow among the sampled geographic sites. We 532 estimated $S p$ values for populations with at least five sampling sites and 20 individuals, i.e., the 533 Hyrcanian (pink) and the Central Armenian (blue) wild apple populations. $S p$ values were low

534 but significant $(S p$ Hyrcanian_pink $=0.0076, S p$ Central_blue $==0.0027, P<0.001)$ suggesting a high

535 level of historical gene flow within populations. However, the $S p$ value was higher for the Iranian 536 population than for the Armenian population suggesting a lower level of historical gene flow 537 within the Hyrcanian (pink) population than the Central Armenian (blue) population. Our results 538 therefore suggest substantial crop-crop, crop-wild and wild-wild gene flow in apples in Iran and 539 the Caucasus.

541 Range expansion and contraction of the wild apple $M$. orientalis in the Caucasus associated 542 with the last glacial maximum

543 We investigated the spatial variation of genetic diversity and used ecological niche modeling to

544 test the existence of past range contraction and expansion for the wild apple in the Caucasus.

545 After removing the 150 crop-wild hybrids identified from the second STRUCTURE analyses, we 546 found a significant positive correlation between longitude and allelic richness (Figure S8, average 547 adjusted $R$-squared $=0.66, P<0.0001)$ and a significant negative correlation between latitude 548 and allelic richness (Figure S8, average adjusted $R^{2}=-0.43, P<0.001$ ). We also found that the 549 western (orange) population had the highest level of allelic richness (Tables 1 and S7 and Figure 550 4). The western Caucasus may therefore have been a glacial refugium in the past. In addition to 551 high levels of genetic diversity in the west, across northeastern Turkey and the Lesser Caucasus 552 mountains in Armenia, we observed local hotspots of genetic diversity in the Hyrcanian Forests 553 and the High Caucasus mountains (Figure 4) suggesting that these mountainous regions may have 554 been potential glacial refugia. 
Ecological niche modeling further indicated past contraction and expansion of the $M$. orientalis range. Model performance as assessed with AUC and TSS was high (Table S11), indicating that the ANN, GLM and GAM algorithms fitted the data well (Allouche, Tsoar, \& 558 Kadmon, 2006; Fieldings \& Bell, 1997; Monserud \& Leemans, 1992). The following six bioclimatic variables were found to have high predictive power: mean diurnal range temperature (bio2), temperature seasonality (bio4), minimum temperature of the wettest quarter (bio8), minimum temperature of the driest quarter (bio9), annual precipitation (bio12) and precipitation of the coldest quarter (bio19). These bioclimatic variables were used to calibrate the models to predict the past and present distribution of M. orientalis. The MIROC model (Figure 4) predicted that the areas suitable for $M$. orientalis during the LGM contracted to the western Lesser Caucasus and northeastern Turkey along the Black Sea and into the Colchis region, and also in the eastern part of the Hyrcanian Forests, near Azerbaijan, in agreement with the genetic data (Figure 4). The climatic model therefore suggested that populations of the Caucasian wild apple M. orientalis may have been maintained in at least two glacial refugia.

\section{Discussion}

571 Our study provides insights into the natural and anthropogenic divergence history of apples in a

572 hotspot of crop diversity, the Caucasus. First, we identified two distinct cultivated gene pools in 573 Iran that were well differentiated from the standard $M$. domestica apple cultivars and were not 574 derived from $M$. sieversii or $M$. domestica. Our results thus suggest that Iran is an additional 575 center of apple domestication. Second, we showed that the evolution of the domesticated apple 576 involved an additional wild species: $M$. orientalis. Indeed, cultivated apple from the Caucasus 577 belonged to the Caucasian $M$. orientalis gene pool, suggesting that local farmers use the

578 Caucasian crabapple for cultivation. Furthermore, M. orientalis has contributed to the Caucasian 579 cultivated apple germplasm through wild-to-crop introgression; a similar process has been 580 previously described in apples in Europe (Cornille et al., 2014, 2012). Reciprocally, we detected 581 crop-to-wild gene flow in the Caucasus, as it has been reported in Europe (Cornille et al., 2015).

582 Third, «pure » $M$. orientalis in this region showed a clear spatial genetic structure with at least 583 seven populations spread across the Caucasus. The combination of niche modeling and 584 population genetics approaches suggested that these populations resulted from range contraction 585 and expansion associated with the last glaciation. Thus, this study revealed the existence of an 
additional center of apple domestication, which seems to have followed processes that are strikingly similar to those observed in Europe, i.e., substantial wild-to-crop and crop-crop gene flow. Several origins of domestication with substantial hybridization between domestic and wild forms have also been described in other fruit trees (Groppi, Liu, Cornille, Decroocq, \& Decroocq, 2021; Liu et al., 2019; Wu et al., 2018).

An additional center of apple domestication in Iran, with two specific cultivated gene pools

\section{that originated independently}

594 The occurrence of two specific cultivated populations in Iran, which are genetically differentiated

595 from the cultivated apple $M$. domestica and are not derived from $M$. sieversii or M. domestica,

596 suggests that Iran is an additional center of apple domestication. Domesticated populations are 597 expected to be nested within their source population because they recently diverged from a subset 598 of individuals within the source population (Matsuoka et al., 2002); however, the green Iranian 599 cultivated population was not nested within any wild population (by contrast, M. domestica that 600 was nested within $M$. sieversii) suggesting that, despite our considerable sampling effort, we have 601 so far been unable to identify the wild population that is most closely related to this cultivated 602 (green) population. The purple Iranian cultivated population was nested within the wild purple 603 population, but the status of this wild purple population (either feral or wild trees that are 604 cultivated) remains unclear as we lack phenotypic data (see below). However, the monophyly of 605 the two Iranian cultivated groups (green and purple) suggests that they diverged from the same 606 wild population, perhaps corresponding to two successive domestication steps, or represent 607 independent domestication events from the same progenitor. We tested these hypotheses and 608 inferred more precisely the Iranian cultivated apple domestication history using coalescent-based 609 methods combined with approximate Bayesian computation. We confirmed that the two Iranian 610 cultivated populations did not diverge from $M$. sieversii or $M$. domestica, but independently from 611 the same ancestral, unidentified population. Thus, despite the spread of the cultivated apple $M$. 612 domestica along the Silk Trade Routes that crossed Iran and the South Caucasus to reach Turkey 613 (Canepa, 2010; Spengler, 2019), specific domestication events in this region led to local 614 cultivated apple gene pools.

615 The occurrence of independent domestication events in many crop species is a source of 616 ongoing debate (Besnard et al., 2018; Choi et al., 2017; Gros-Balthazard \& Flowers, 2021). In 
617 apricot and pear, there is evidence of independent domestication events in Europe and Asia

618 (Groppi et al., 2021; Liu et al., 2019; Wu et al., 2018). Although we could not identify the source

619 population of the Iranian cultivated apple populations, our demographic inferences provide strong

620 support for domestication from an ancestral gene pool other than M. sieversii from Kazakhstan.

621 Distinct genetic ancestries may not reflect independent de novo domestication, but may instead

622 represent a single domestication event with multiple origins (Choi et al., 2017; Gros-Balthazard

$623 \&$ Flowers, 2021). We cannot ascertain that there were independent domestication events as we

624 could not identify the source population. However, our data shows that the cultivated apple had

625 multiple origins and was derived from distinct ancestral gene pools, irrespective of whether the

626 ancestral populations were independently domesticated. Studies of the regions under selection

627 during domestication in the Iranian and European cultivated apple genomes will likely provide

628 insights into whether multiple de novo domestication events occurred. Independent selection

629 regimes in each of the cultivated genetic groups would be a hallmark of multiple domestications.

631 The genetic relationships between the two wild contributors and the status of the wild 632 Hyrcanian purple population are still unclear

633 The relationship between $M$. sieversii and M. orientalis is still unclear. We found that M. sieversii

634 from Kazakhstan was nested within the $M$. domestica gene pool, while M. sieversii from 635 Kyrgyzstan was closer to M. orientalis from the Zagros and Hyrcanian regions. Malus orientalis

636 thus seems to be polyphyletic and intermingled with $M$. sieversii. Deciphering the relationship 637 between $M$. sieversii and $M$. orientalis, and even the species status of $M$. orientalis, is not only a 638 taxonomic exercise but is needed to better understand apple domestication. This question needs 639 to be resolved urgently, M. sieversii being endangered across its distribution (Omasheva et al., 640 2017; H.-X. Zhang, Li, \& Li, 2018), as confirmed here by the lower level of genetic diversity of 641 the $M$. sieversii population in Kyrgyzstan. Likewise, the status of the wild purple population in 642 the Hyrcanian Forests is still unclear. Individual trees are isolated in mountainous areas, but 643 found close to grafted fruit trees on Craetagus, although they are not cultivated (personal 644 observation. H. Yousefzadeh). Like domestication, feralization can be seen as a process that is 645 accompanied by admixture and introgression, and can be accompanied by a range of genetic, 646 phenotypic and demographic changes (Mabry, Rowan, Pires, \& Decker, 2021). The purple wild 647 population had a lower level of genetic diversity than the other wild Iranian population, which 
648 may suggest that this population has recently escaped from cultivation. Feral populations have 649 also been found in other fruit trees including olive (Besnard et al., 2018), almond (Balaguer650 Romano et al., 2021) and apricot (Robert N. Spengler, Chang, \& Tourtellotte, 2013). However, 651 the purple population found in the Hyrcanian Forests could also be the result of a first 652 domestication step, as wild apples are widely used for cultivation in Iran (personal 653 communication $\mathrm{H}$. Yousefzadeh). Additional phenotyping of cultivated and wild Iranian 654 populations, and possibly historical records, are now required to better understand whether those 655 trees represent an ongoing domestication event or form a feral population.

\section{Malus orientalis is an additional contributor to the cultivated apple gene pool}

658 It seems that local farmers in the Caucasus grow the local wild $M$. orientalis rather than $M$. 659 domestica. Indeed, the four Armenian cultivars shared their gene pools with the Western (orange) 660 and Central (blue) Caucasian wild apple populations, and Iranian cultivars were highly admixed 661 and even in some cases fully assigned to wild populations (red and purple) in Iran. This is not 662 surprising as this wild species can grow in mountainous areas, is highly resistant to pests, 663 diseases and drought (Amirchakhmaghi et al., 2018; Büttner, 2001; Höfer et al., 2013; Volk et al., 664 2008) and has high-quality fruits that have several features that are intermediate between those of 665 M. sylvestris and M. sieversii (Cornille et al., 2014). The use of the local wild apples has also 666 been documented in Europe for specific purposes at different times in history (Tardío, Arnal, \& 667 Lázaro, 2020).

668 The Caucasian crab apple has also considerably contributed to the Caucasian apple 669 germplasm through wild-to-crop introgression. We found evidence of substantial wild-crop and 670 crop-crop gene flow in the Caucasus. Indeed, we found that $41.6 \%$ of Iranian cultivars were 671 introgressed by local wild apple gene pools or were an admixture of two cultivated gene pools. 672 This extensive wild-to-crop and crop-crop gene flow is strikingly similar to the pattern 673 documented in apples in Europe. Malus sylvestris has been shown to be a significant contributor 674 to the $M$. domestica gene pool through recurrent and recent hybridization and introgression 675 events ever since the cultivated apple was introduced in Europe by the Greeks around 1,500 years 676 ago (Cornille et al., 2012). Reciprocally, substantial crop-to-wild gene flow has been reported 677 from M. domestica to M. sylvestris (Cornille et al., 2015). Similarly, we found many crop-to-wild 678 hybrids, from $M$. domestica to M. orientali,s in the forests of Armenia and Iran, as observed in 
679 apples in Europe (Cornille et al., 2015). Extensive gene flow has been found during the 680 domestication of other fruit trees (Arroyo-García et al., 2006; Cornille et al., 2012; Decroocq et 681 al., 2016; Diez et al., 2015; Duan et al., 2017; Liu et al., 2019; Meyer, Duval, et al., 2012; Myles

682 et al., 2011). The evolutionary consequences of crop-to-wild gene flow remains unclear in fruit 683 trees (Feurtey, Cornille, Shykoff, Snirc, \& Giraud, 2017a); the extent to which crop-to-wild gene 684 flow may threaten the local Caucasian crab apple remains to be tested.

686 The natural divergence history of the Caucasian wild apple was shaped by the last 687 glaciation

688 The climatic variations since the last glacial maximum, along with the landscape features of the 689 Caucasus, have likely shaped the population structure and diversity of the Caucasian wild apple. 690 We identified seven populations of M. orientalis in the Caucasus and Iran: one highly genetically 691 differentiated population in the Western Caucasus (Turkey, Russia and northwestern Armenia), 692 two in Armenia (a southern and a Central population) and four in Iran, including two in the 693 Zagros Forest (one in the Kurdestan province and one in the Lorestan province) and two in the 694 Hyrcanian Forests bordering the southern Caspian Sea. These wild apple populations likely arose 695 from isolation in several refugia during the last glacial maximum. This hypothesis is supported by 696 the observation of a large hotspot of genetic diversity located in Western Caucasus, and several 697 local hotpots of genetic diversity in Armenia and the Hyrcanian Forests (Zazanashvili et al., 698 2020). Ecological niche modeling further supported the existence of strong contractions in the 699 range of $M$. orientalis in the Western Caucasus bordering the Black Sea (including the Colchis 700 region), as well as in the Lesser Caucasus and in some parts of the Hyrcanian Forests. Additional 701 samples from the Western Caucasus are required to confirm this hypothesis. These glacial refugia 702 have been described in relation to other species (Parvizi et al., 2019). Indeed, two refugia are 703 recognized in the Caucasus (Tarkhnishvili et al. 2012; Yousefzadeh et al. 2012; Bina et al. 2016; 704 Aradhya et al. 2017): a major forest refugium between the western Lesser Caucasus and 705 northeastern Turkey (including the Colchis region in the catchment basin of the Black Sea) and 706 the Hyrcanian refugium at the southern edge of the Caucasus. Further sampling of M. orientalis 707 in the far Western and Eastern Caucasus and genotyping with the same microsatellite markers is 708 needed to uncover the role of these two refugia for M. orientalis. 
We also found that the natural divergence history of the Caucasian wild apple involved gene flow across the Caucasus. The weak but significant isolation-by-distance pattern further

711 supported the existence of substantial gene flow among wild apple populations in the Caucasus.

712 Widespread gene flow during divergence associated with the last glacial maximum has been

713 documented for another wild apple relative M. sylvestris (Cornille et al., 2013). Calculation of the

$714 S p$ parameter within the largest populations revealed high levels of historical gene flow within

715 populations. $S p$ can also be used to compare the dispersal capacities of $M$. orientalis with that of

716 other plants (Cornille et al., 2013; Cornille et al., 2013a; Vekemans \& Hardy, 2004b). The

717 Caucasian wild apple showed dispersal capacities that were similar to previous estimates in other

718 wild apple species and lower than that of wind-dispersed trees. Wild apples can thus spread over

719 kilometers (Cornille et al., 2015; Feurtey, Cornille, Shykoff, Snirc, \& Giraud, 2017). The spatial

720 population structure was somewhat stronger in Iran than in Armenia suggesting lower levels of

721 gene flow in the Hyrcanian population. In addition to having a stronger genetic structure, the

722 Iranian populations had lower genetic diversity then the Armenian populations, especially the

723 Zagros and Kurdestan populations. In Iran, traditional animal husbandry is a widespread practice

724 (Soofi et al., 2018). Such intensive farming environments may lead to forest fragmentation and

725 may impact wild apple populations, which form low density populations. The future of Iranian

726 wild apple populations, especially in the south where genetic diversity is low, will depend on our

727 ability to protect them through sustainable conservation programs.

728

\section{Conclusion}

730 We identified Iran as a key center in the evolution and domestication of apple, and M. orientalis

731 as an additional contributor to the evolutionary history of cultivated apple. We also provided

732 insights into the processes underlying the natural divergence of this emblematic wild species and

733 identified several populations that could be the target of conservation programs. However, $M$.

734 orientalis in the Caucasian ecoregion is highly diverse and further investigations and additional

735 sampling are necessary, as well as a better assessment of its species status and genetic

736 relationship with $M$. sieversii. Indeed, a better understanding of the properties of functional

737 genetic diversity and the ecological relationship of wild apples in their ecosystem is needed for

738 developing and implementing effective conservation genetic strategies in this region (Teixeira \&

739 Huber, 2021). Our study revealed the role of gene flow and human practices in natural and 
740 anthropogenic divergence processes of an emblematic fruit tree in the Caucasus. Our results are

741 consistent with those reported for other woody perennials, including apricots (Groppi et al., 2021;

742 Liu et al., 2019), olive (Besnard et al., 2018; Diez et al., 2015), pears (Volk \& Cornille, 2019; Wu

743 et al., 2018), or date palms (Flowers et al., 2019). This study also supports the view that

744 domestication of fruit trees was likely a geographically diffuse and protracted process, involving

745 multiple, geographically disparate origins of domestication (Groppi et al., 2021; Wu et al., 2018).

\section{Acknowledgements}

748 We thank the Franco-Iranian Campus France program «Gundhishapur » 2016-2018, the Institut

749 Diversité Écologie et Évolution du Vivant (IDEEV) and ATIP-Avenir for funding. We thank

750 Bolotbek Tagaev (Sustainable Livelihoods Coordinator of FFI-Kyrgyzstan) for sampling and

751 prospection, Fauna \& Flora International and more specifically the Global Trees Campaign

752 (GTC) Program. We also thank Adrien Falce, Olivier Langella and Benoit Johannet for help and

753 support on the INRAE-Génétique Quantitative et Evolution- Le Moulon lab cluster and the

754 genotyping platform GENTYANE INRA UMR 1095. We thank the INRAE MIGALE

755 bioinformatics platform (http://migale.jouy.inra.fr) for providing help and support, in particular

756 Véronique Martin, Eric Montaubon and Valentin Loux. We also thanks Céline Bellard for her

757 advices for ecological niche modeling analyses.

758 Data Availability

759 SSR data are available on the DRYAD repository XXXX.

761 AC, HY conceived and designed the experiments; AC, HY obtained funding; HB, HY, SF, HBa, 762 IG, AN, AC, JS, DG, AK sampled the material; AV, CR, AR, MF performed the molecular work; 763 AC, HB analyzed the data; AC, HB, HY: wrote the original draft and preparation of the figures;

764 AC, HB, HY, TG, XC, IG, AN and all co-authors: gave critical inputs in final draft and revisions. 

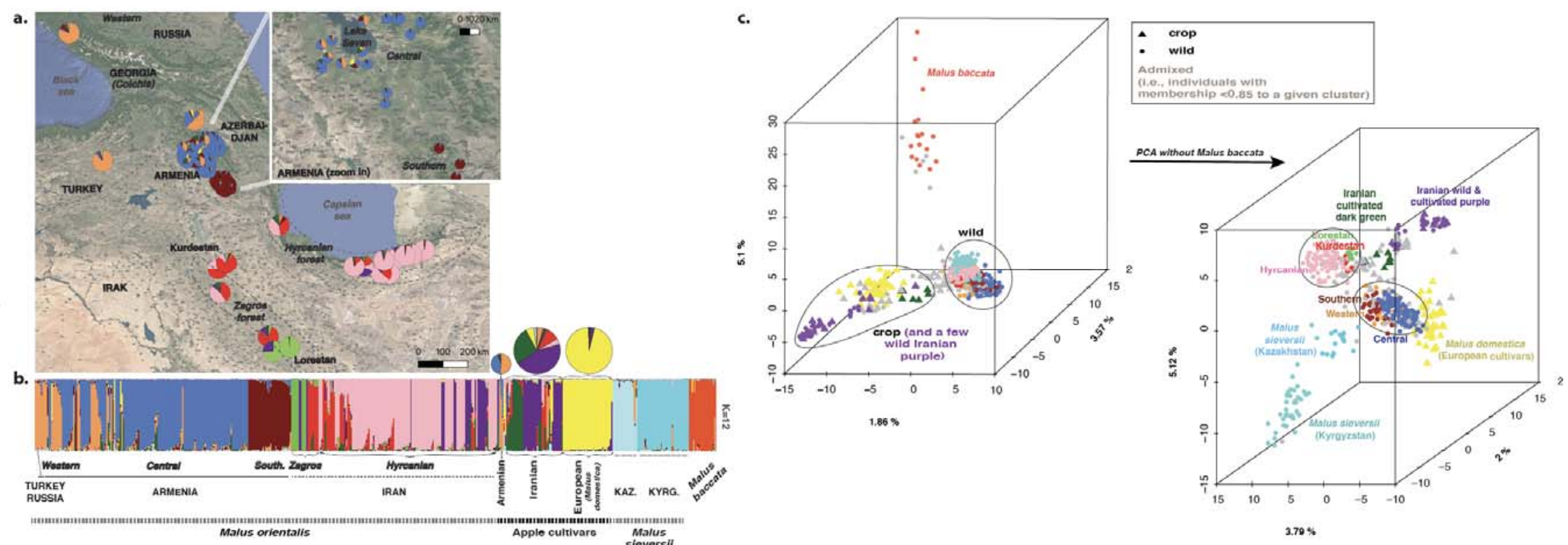

$3.70 \%$

Figure 1. Population genetic structure and differentiation in cultivated and wild apples from the Caucasus, Malus domestica,

Malus sieversii and Malus baccata based on 26 microsatellite markers. a. Spatial population genetic structure inferred with STRUCTURE at $K=12(N=550)$; the map represents membership proportions averaged over each geographic site for the Caucasian wild apple $M$. orientalis ( $N=374,43$ sites across Turkey, Russia, Armenia and Iran). In the bottom right corner, the mean membership proportions for the apple cultivars from Armenia $(N=4)$, Iran $(N=48)$ and Europe $(M$. domestica, $N=40)$. The size of the pie charts is proportional to the number of samples per site. b. STRUCTURE bar plot $(N=550)$ at $K=12$ showing 12 distinct genetic clusters. Each vertical line represents an individual. Colors represent the inferred ancestry from $K$ ancestral genetic clusters. Sites are grouped by country for the wild apple samples (i.e., Turkey, Russia, Armenia, Iran) and M. sieversii (i.e., Kazakhstan and Kyrgyzstan), apple cultivars are grouped according to their origin: Armenia $(N=4)$, Iran $(N=48)$ and $M$. domestica $(N=40)$. Countries $(\operatorname{Kazakhstan}$, 
778 Kyrgyzstan, Armenia) and/or main regions in the Caucasus (the Western Caucasus, i.e., Turkey and Russia, Zagros and Hyrcanian

779 Forests, Central and Southern Armenia) are shown on the map. Reference samples from previously published studies of each species

780 are: $M$. orientalis from the Western Caucasus and Central and Southern Armenia, M. domestica (European cultivars), M. sieversii from

781 Kazakhstan (Cornille et al., 2013a) and M. baccata (Cornille et al., 2012) c. Principal component analysis (PCA) of 550 individuals

782 (upper left), and after removing the outgroup $M$. baccata (lower right, $N=530$ ), with the respective total variation explained by each

783 component. 
a.

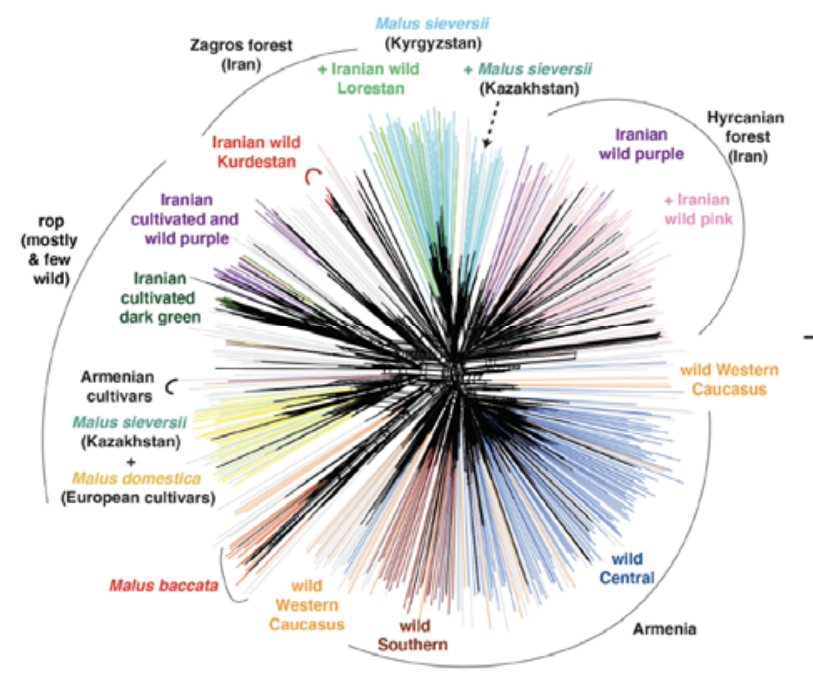

b.

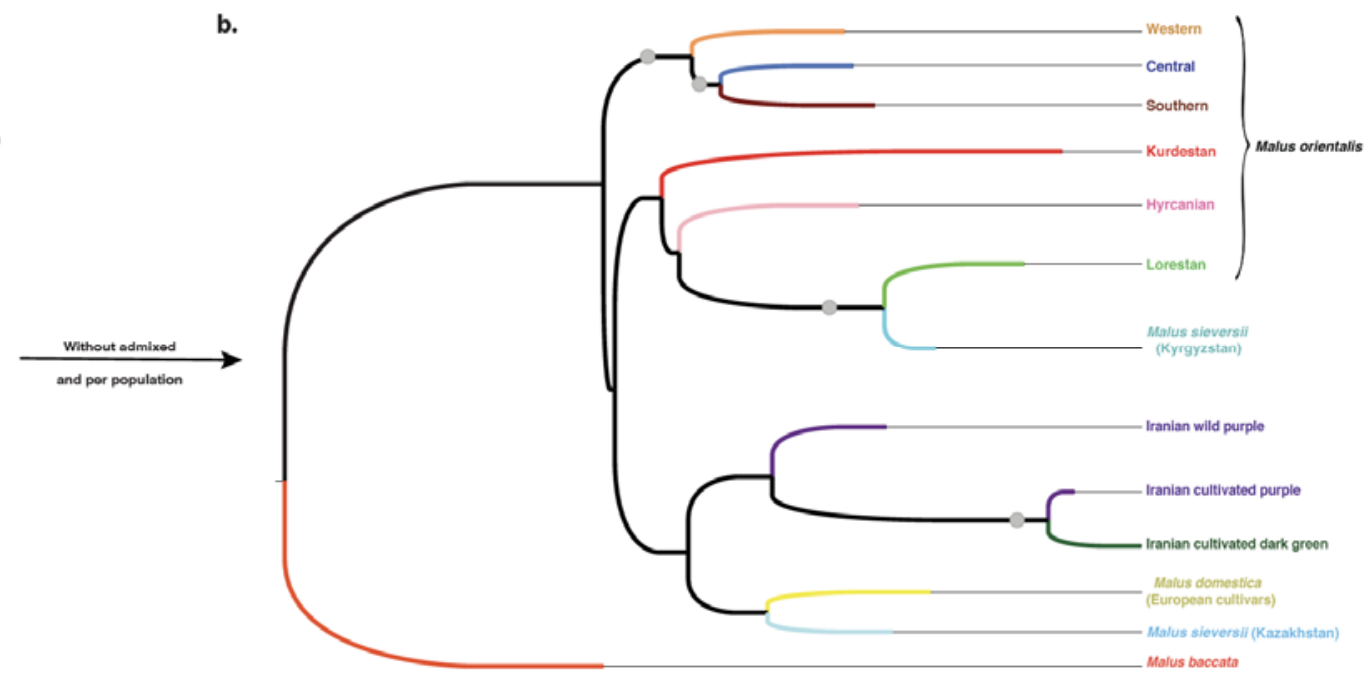

Figure 2. Genetic differentiation among cultivated and wild apples from the Caucasus, Malus domestica, Malus sieversii and Malus baccata based on 26 microsatellite markers. a. Neighbor-net representing the genetic relationships among wild and cultivated individuals inferred with STRUCTURE at $K=12$. Colors correspond to the genetic groups inferred with STRUCTURE at $K=12$ and admixed samples are in grey. b. Neighbor-joining tree representing the distance among the twelve populations detected with STRUCTURE at $K=12$, excluding admixed individuals (i.e., individuals with a membership coefficient $<0.85$ to any given cluster), and rooted with $M$. baccata. Each branch is coloured according to the population inferred with STRUCTURE at $K=12$, nodes with a grey

circle

represent

bootstrap

values

$80 \%$. 


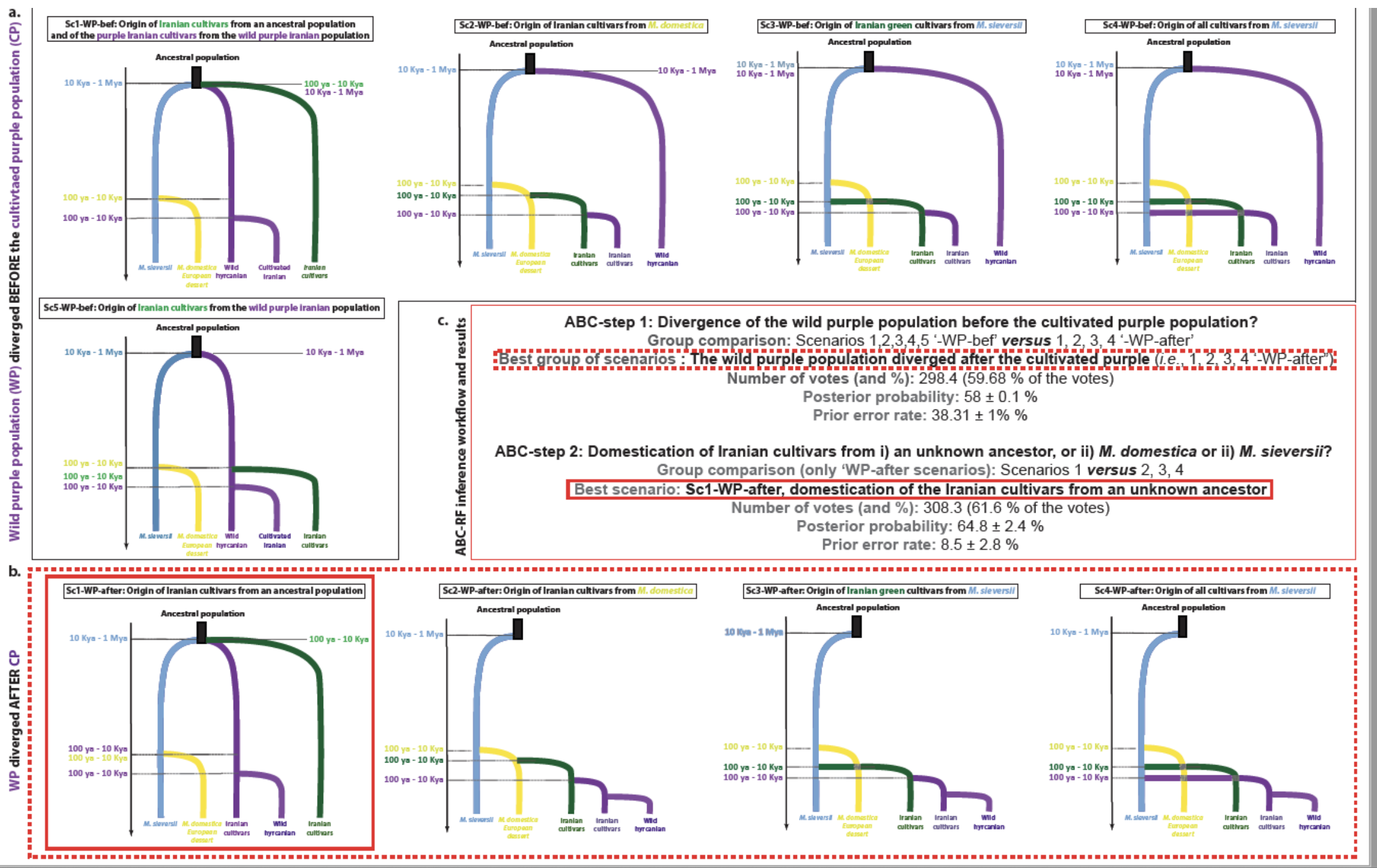

Figure 3. Inference of independent domestication events of cultivated apples in Iran using random-forest approximate 
(sc1-WP-bef, sc2-WP- bef, sc3-WP- bef, sc4-WP- bef, sc5-WP- bef). b. Four scenarios testing the domestication history of Iranian cultivars (purple and green) assuming the wild Iranian purple population diverged more recently than the cultivated purple (sc1-WPafter, sc2-WP-after, sc3-WP-after, sc4-WP-after). For a and b, scenarios assumed bidirectional gene flow between crop and wild populations. c. Most likely groups of scenarios (step 1) or scenario (step 2) of Iranian apple domestication inferred from ABC-RF analyses. The corresponding most likely scenarios, or groups of scenarios, are framed in red (dashed or solid lines for steps 1 and 2 , respectively). Population names correspond to the ones detected with STRUCTURE for $K=12$, excluding admixed individuals (i.e., individuals with a membership coefficient $<0.85$ to any given cluster). 


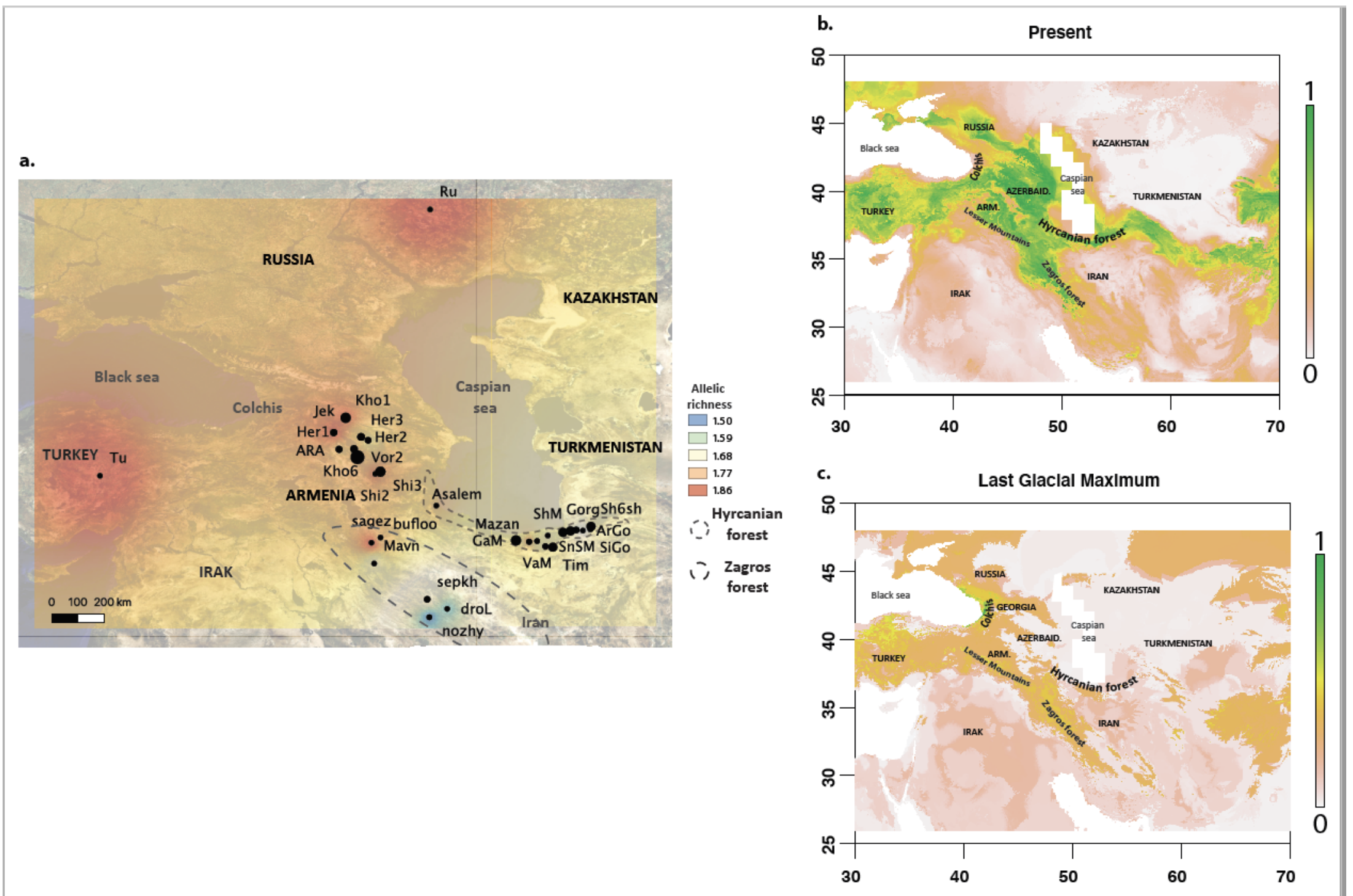

Figure 4. Spatial diversity and past contraction and expansion of Malus orientalis across the Caucasus. Spatial genetic diversity 
1 (allelic richness) at 36 sites $(\boldsymbol{N}=\mathbf{3 3 9})$. b. Ensemble forecasting of the three different algorithms (ANN, GLM and GAM) predicting

2 the current (a) and last glacial maximum (LGM) (b) distribution range of suitable areas for M. orientalis. The probabilities of being a

3 suitable habitat are given in the legend. The Colchis and Hyrcanian regions are shown on the maps. 
1 Table 1. Genetic diversity estimates for wild and cultivated apple populations detected with STRUCTURE at $K=12(N=424$,

2 i.e., individuals with a membership coefficient $<0.85$ to any given cluster were excluded from the analysis). Note that the purple

3 cluster was split between cultivated and wild samples. Thus, samples were partitioned into 13 populations, including 10 wild and three

4 cultivated apple populations.

\begin{tabular}{|c|c|c|c|c|c|c|c|c|c|}
\hline Wild or cultivated & Species & $\begin{array}{c}\text { Country of } \\
\text { origin }\end{array}$ & Population & $N$ & $H_{O}$ & $H_{E}$ & $F_{I S}$ & $A_{R}(G=7)$ & $A_{P}(G=7)$ \\
\hline \multirow[t]{10}{*}{ wild } & \multirow{7}{*}{ 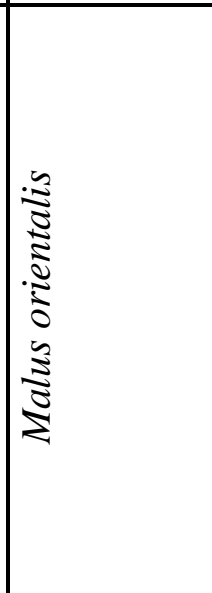 } & \multirow[t]{3}{*}{ Armenia } & Western (orange) & 20 & 0.82 & 0.86 & $0.05 * *$ & $5.04 \pm 0.13$ & $0.97 \pm 0.10$ \\
\hline & & & Central (blue) & 109 & 0.78 & 0.79 & $0.01^{\mathrm{NS}}$ & $4.03 \pm 0.14$ & $0.60 \pm 0.08$ \\
\hline & & & Southern (brown) & 29 & 0.76 & 0.79 & $0.03^{\mathrm{NS}}$ & $4.38 \pm 0.17$ & $0.63 \pm 0.12$ \\
\hline & & \multirow[t]{4}{*}{ Iran } & $\begin{array}{c}\text { Lorestan (light } \\
\text { green) }\end{array}$ & 10 & 0.84 & 0.46 & $-0.82 * * *$ & $2.03 \pm 0.12$ & $0.23 \pm 0.06$ \\
\hline & & & Kurdestan (red) & 12 & 0.75 & 0.71 & $-0.05 *$ & $3.71 \pm 0.15$ & $0.50 \pm 0.09$ \\
\hline & & & Hyrcanian (pink) & 88 & 0.71 & 0.76 & $\mathbf{0 . 0 7} * * *$ & $4.12 \pm 0.18$ & $0.65 \pm 0.10$ \\
\hline & & & Hyrcanian (purple) & 19 & 0.76 & 0.63 & $-0.21 * * *$ & $3.24 \pm 0.13$ & $0.21 \pm 0.03$ \\
\hline & \multirow{2}{*}{$\begin{array}{c}\text { Malus } \\
\text { sieversii }\end{array}$} & Kazahkstan & (light blue) & 40 & 0.74 & 0.76 & $\mathbf{0 . 0 3} *$ & $4.15 \pm 0.16$ & $0.99 \pm 0.13$ \\
\hline & & Kyrkyzstan & (cyan) & 17 & 0.70 & 0.73 & $0.04 *$ & $3.47 \pm 0.14$ & $0.30 \pm 0.06$ \\
\hline & $\begin{array}{c}\text { Malus } \\
\text { baccata }\end{array}$ & Russia & (light red) & 17 & 0.52 & 0.55 & $0.06^{\mathrm{NS}}$ & $3.23 \pm 0.19$ & $1.08 \pm 0.14$ \\
\hline cultivated & $\begin{array}{c}\text { Malus } \\
\text { domestica }\end{array}$ & $\begin{array}{l}\text { Mostly } \\
\text { Europe }\end{array}$ & European cultivars & 38 & 0.78 & 0.78 & $-0.00^{\mathrm{NS}}$ & $4.27 \pm 0.09$ & $0.85 \pm 0.10$ \\
\hline
\end{tabular}




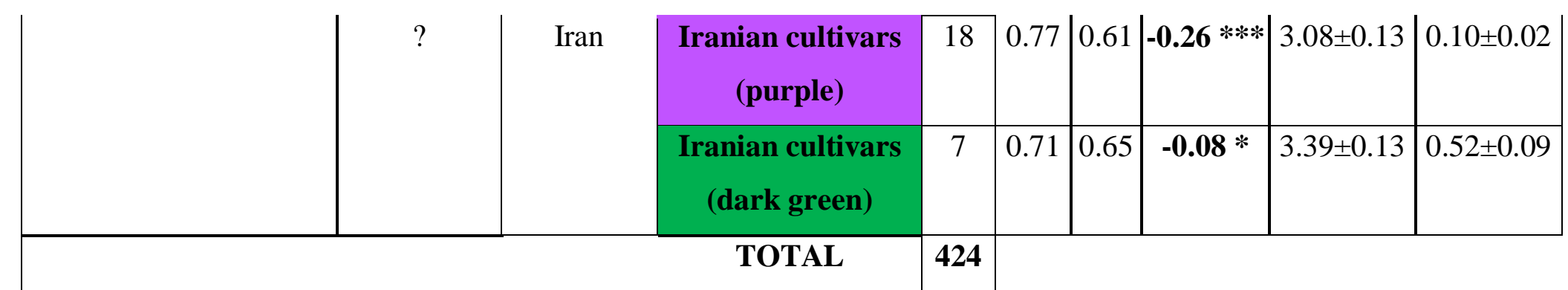

1

$2 N$ : number of individuals assigned to a focal cluster with a membership coefficient $>0.85 ; H_{O}$ and $H_{E}$ : observed and expected

3 heterozygosity; $F_{I S}$ : inbreeding coefficient; $A_{R}$ : mean allelic richness across loci, corrected by the rarefaction method, estimated for a

4 sample size of 7; $A_{P}$ : number of private alleles, corrected by the rarefaction method, estimated for a sample size of 7 ; $* 0.05<P<$

$5 \quad 0.01 ; * * *: P<0.001 ;$ NS : non-significant. 
Table 2. Distribution of hybrids (i.e., individuals with a membership coefficient $<0.90$ to any given genetic cluster, as inferred 2 with STRUCTURE for $K=9)$ in cultivated and wild apple in the Caucasus $(N=466,26$ microsatellite markers). For each group

3 (cultivated or wild, from different regions), $N_{\text {tot }}$ is the total number of samples in each group, $N$ is the number of hybrids assigned to 4 each gene pool and \% is the respective percentage over the total number of samples from each group, the mean introgression rate is the 5 mean membership coefficient to this gene pool. Note that some admixed trees were assigned to several gene pools with a membership 6 coefficient < 0.90; the total number of hybrids associated with each cluster (TOTAL) is given on the last line of the table. We also 7 showed the distribution of crop-crop, crop-to-wild, wild-to-crop and wild-to-wild hybrids.

\begin{tabular}{|c|c|c|c|c|c|c|c|c|c|}
\hline \multirow[b]{2}{*}{ Genepool } & & \multicolumn{3}{|c|}{ Crop } & & \multicolumn{4}{|c|}{ Wild } \\
\hline & & $\begin{array}{c}\begin{array}{c}\text { Armeni } \\
\mathrm{a}\end{array} \\
N_{t o t}=3\end{array}$ & $\begin{array}{c}\text { Iran } \\
N_{t o t}=48\end{array}$ & $\begin{array}{c}M . \\
\text { domestic } \\
a \\
N_{t o t}=40\end{array}$ & & $\begin{array}{l}\text { Armeni } \\
\mathrm{a} \\
N_{t o t}=19 \\
6\end{array}$ & $\begin{array}{c}\text { Iran } \\
N_{t o t}=16 \\
7\end{array}$ & $\begin{array}{l}\text { Russi } \\
\mathrm{a} \\
N_{\text {tot }}=5\end{array}$ & $\begin{array}{l}\text { Turkey } \\
N_{t o t}=6\end{array}$ \\
\hline \multirow[t]{2}{*}{ Malus domestica } & $\begin{array}{c}\text { mean } \\
\text { introgression rate }\end{array}$ & 0 & 0.13 & 0.66 & & 0.04 & 0.02 & 0 & 0 \\
\hline & $\begin{array}{c}\mathrm{N} \text { (\% over the } \\
\text { total) }\end{array}$ & 0 & $\begin{array}{c}11 \\
(23 \%)\end{array}$ & $2(5 \%)$ & & $4(2 \%)$ & $\begin{array}{c}5 \\
(2.9 \%)\end{array}$ & 0 & 0 \\
\hline \multirow{2}{*}{$\begin{array}{l}\text { Wild and } \\
\text { cultivated } \\
\text { Hyrcanian } \\
\text { (purple) }\end{array}$} & $\begin{array}{c}\text { mean } \\
\text { introgression rate }\end{array}$ & 0 & 0.36 & 0.33 & & 0 & 0.16 & 0 & 0 \\
\hline & $\mathrm{N}(\%)$ & 0 & $\begin{array}{c}18 \\
(37.5 \% \\
)\end{array}$ & $2(5 \%)$ & & $\overline{0}$ & $\begin{array}{c}13 \\
(7.8 \%)\end{array}$ & 0 & 0 \\
\hline \multirow[t]{3}{*}{$\begin{array}{c}\text { Cult. Iran } \\
\text { (dark_green) }\end{array}$} & $\begin{array}{c}\text { mean } \\
\text { introgression rate }\end{array}$ & 0 & 0.17 & 0 & & 0.05 & 0.06 & 0 & 0 \\
\hline & $\mathrm{N}(\%)$ & 0 & $\begin{array}{c}14 \\
(30 \%)\end{array}$ & 0 & & $\begin{array}{c}11 \\
(5.6 \%)\end{array}$ & $\begin{array}{c}8 \\
(4.7 \%)\end{array}$ & 0 & 0 \\
\hline & $\begin{array}{c}\text { Ncrop-crop } \\
\text { hybrids (and \%) }\end{array}$ & 0 & $\begin{array}{c}43 \\
(89.5 \%\end{array}$ & $4(1 \%)$ & $\begin{array}{l}\text { Ncrop-to-wild } \\
\text { hybrids (and }\end{array}$ & $\begin{array}{c}15 \\
(7.6 \%)\end{array}$ & $\begin{array}{c}26 \\
(18.1 \%\end{array}$ & $\mathbf{0}$ & $\mathbf{0}$ \\
\hline
\end{tabular}




\begin{tabular}{|c|c|c|c|c|c|c|c|c|c|}
\hline & & & ) & & $\%)$ & & ) & & \\
\hline \multirow[t]{2}{*}{ Hyrcanian (pink) } & $\begin{array}{c}\text { mean } \\
\text { introgression rate }\end{array}$ & 0 & 0.05 & 0 & & 0 & 0.41 & 0 & 0 \\
\hline & $\mathrm{N}(\%)$ & 0 & $\begin{array}{c}6 \\
(12.5 \% \\
)\end{array}$ & 0 & & 0 & $\begin{array}{c}34 \\
(20.3 \% \\
)\end{array}$ & 0 & 0 \\
\hline \multirow[t]{2}{*}{$\begin{array}{l}\text { Lorestan (light } \\
\text { green) }\end{array}$} & $\begin{array}{c}\text { mean } \\
\text { introgression rate }\end{array}$ & 0 & 0.01 & 0 & & 0 & 0.04 & 0 & 0 \\
\hline & $\mathrm{N}(\%)$ & 0 & $2(4 \%)$ & 0 & & 0 & $\begin{array}{c}6 \\
(3.6 \%)\end{array}$ & 0 & 0 \\
\hline \multirow[t]{2}{*}{$\begin{array}{l}\text { Wild Kurdistan } \\
\text { (red) }\end{array}$} & $\begin{array}{c}\text { mean } \\
\text { introgression rate }\end{array}$ & 0 & 0.17 & 0 & & 0 & 0.27 & 0 & 0 \\
\hline & $\mathrm{N}(\%)$ & 0 & $\begin{array}{c}12 \\
(35 \%)\end{array}$ & 0 & & 0 & $\begin{array}{c}30 \\
(17.9 \% \\
)\end{array}$ & 0 & 0 \\
\hline \multirow[t]{2}{*}{ Western (orange) } & $\begin{array}{c}\text { mean } \\
\text { introgression rate }\end{array}$ & 0.65 & 0.08 & 0 & & 0.28 & 0.02 & 0.49 & 0.84 \\
\hline & $\mathrm{N}(\%)$ & $\begin{array}{c}1 \\
(33 \%)\end{array}$ & $\begin{array}{c}3 \\
(6.2 \%)\end{array}$ & 0 & & $\begin{array}{c}33 \\
(16.8 \% \\
)\end{array}$ & $\begin{array}{c}4 \\
(2.3 \%)\end{array}$ & $\begin{array}{c}1 \\
(20 \% \\
)\end{array}$ & $\begin{array}{c}2 \\
(33 \%)\end{array}$ \\
\hline \multirow[t]{2}{*}{ Southern (brown) } & $\begin{array}{c}\text { mean } \\
\text { introgression rate }\end{array}$ & 0 & 0.02 & 0 & & 0.17 & 0.02 & 0.35 & 0 \\
\hline & $\mathrm{N}(\%)$ & 0 & $\begin{array}{c}2 \\
(4.1 \%)\end{array}$ & 0 & & $\begin{array}{c}13 \\
(6.6 \%)\end{array}$ & $\begin{array}{c}2 \\
(1.1 \%)\end{array}$ & $\begin{array}{c}1 \\
(20 \% \\
)\end{array}$ & 0 \\
\hline \multirow[t]{3}{*}{ Central (blue) } & $\begin{array}{c}\text { mean } \\
\text { introgression rate }\end{array}$ & 0.32 & 0.02 & 0 & & 0.46 & 0.01 & 0 & 0.11 \\
\hline & $\mathrm{N}(\%)$ & $\begin{array}{c}1 \\
(33 \%)\end{array}$ & $1(2 \%)$ & 0 & & $\begin{array}{c}46 \\
(23.4 \% \\
)\end{array}$ & $\begin{array}{c}1 \\
(0.5 \%)\end{array}$ & 0 & $\begin{array}{c}1 \\
(16.6 \% \\
)\end{array}$ \\
\hline & $\begin{array}{c}\text { Nwild-to-crop } \\
\text { hybrids (and \%) }\end{array}$ & $\begin{array}{c}2 \\
(66 \%)\end{array}$ & $\begin{array}{c}26 \\
(54.1 \% \\
\end{array}$ & 0 & $\begin{array}{l}\text { Nwild-to-wild } \\
\text { hybrids (and }\end{array}$ & $\begin{array}{c}92 \\
(46.9 \% \\
\end{array}$ & $\begin{array}{c}77 \\
(46.1 \% \\
\end{array}$ & $\begin{array}{c}2 \\
(40 \%\end{array}$ & $\begin{array}{c}3 \\
(50 \%)\end{array}$ \\
\hline
\end{tabular}




\begin{tabular}{|c|c|c|c|c|c|c|c|c|c|}
\hline & & ) & & $\%)$ & ) & ) & ) & & \\
\hline $\begin{array}{l}\text { Total number of } \\
\text { hybrids (and \%) }\end{array}$ & 1 & $\begin{array}{c}32 \\
(66 \%)\end{array}$ & $2(5 \%)$ & & $\begin{array}{c}58 \\
(28 \%)\end{array}$ & $\begin{array}{c}54 \\
(32 \%)\end{array}$ & $\begin{array}{c}1 \\
(20 \% \\
)\end{array}$ & $\begin{array}{c}2 \\
(33 \%)\end{array}$ & $\begin{array}{c}150 \\
(32 \% \\
)\end{array}$ \\
\hline
\end{tabular}




\section{References}

2 Allouche, O., Tsoar, A., \& Kadmon, R. (2006). Assessing the accuracy of species distribution models: Prevalence, kappa and the true skill statistic (TSS). Journal of Applied Ecology, 43(6), 1223-1232.

Amirchakhmaghi, N., Yousefzadeh, H., Hosseinpour, B., Espahbodi, K., Aldaghi, M., \& Cornille, A. (2018). First insight into genetic diversity and population structure of the Caucasian wild apple (Malus orientalis Uglitzk.) in the Hyrcanian forest (Iran) and its resistance to apple scab and powdery mildew. Genetic Resources and Crop Evolution,

Arroyo-García, R., Ruiz-García, L., Bolling, L., Ocete, R., López, M. A., Arnold, C., ... Martinez-Zapater, J. M. (2006). Multiple origins of cultivated grapevine (Vitis vinifera L.

Asanidze, Z., Akhalkatsi, M., Henk, A. D., Richards, C. M., \& Volk, G. M. (2014a). Genetic ssp. Sativa) based on chloroplast DNA polymorphisms. Molecular Ecology, 15(12),

Asanidze, Z., Akhalkatsi, M., Henk, A. D., Richards, C. M., \& Volk, G. M. (2014b). Genetic relationships between wild progenitor pear (Pyrus L.) species and local cultivars native to Georgia, South Caucasus. Flora - Morphology, Distribution, Functional Ecology of Plants, 209(9), 504-512. doi: https://doi.org/10.1016/j.flora.2014.06.013 
Bai, X. N., \& Spitkovsky, A. (2010). Uncertainties of modeling gamma-ray pulsar light curves using vacuum dipole magnetic field. Astrophysical Journal, 715(2), 1270-1281. doi: $10.1088 / 0004-637 X / 715 / 2 / 1270$

Bailey-Serres, J., Parker, J. E., Ainsworth, E. A., Oldroyd, G. E. D., \& Schroeder, J. I. (2019). Genetic strategies for improving crop yields. Nature, 575(7781), 109-118. doi:

Balaguer-Romano, R., Barea-Marquez, A., Ocaña-Calahorro, F. J., Gomez, J. M., Schupp, E. W., $10.1038 / \mathrm{s} 41586-019-1679-0$ naturalization of almond tree. Basic and Applied Ecology, 50, 97-106. doi: 10.1016/j.baae.2020.11.004

Barbet-Massin, M., Jiguet, F., Albert, C. H., \& Thuiller, W. (2012). Selecting pseudo-absence for species distribution models: How, where and how many? Methods in Ecology and Evolution, 3: 327-338.

Besnard, G., Terral, J. F., \& Cornille, A. (2018). On the origins and domestication of the olive: A review and perspectives. Annals of Botany, 121(3), 385-403. doi: 10.1093/aob/mcx145

Bina, H., Yousefzadeh, H., Ali, S. S., \& Esmailpour, M. (2016). Phylogenetic relationships, molecular taxonomy, biogeography of Betula, with emphasis on phylogenetic position of Iranian populations. Tree Genetics and Genomes, 12(5). doi: 10.1007/s11295-016-1037-4

Brandenburg, J. T., Mary-Huard, T., Rigaill, G., Hearne, S. J., Corti, H., Joets, J., ... Tenaillon, M. I. (2017). Independent introductions and admixtures have contributed to adaptation of European maize and its American counterparts. PLoS Genetics, 13(3), 1-30. doi: 10.1371/journal.pgen.1006666

Breiman, L. (2001). Random Forests. Machine Learning, 45(1), 5-32. doi: 10.1023/A:1010933404324 
Browicz, K. (1969). Amygdalus. Flora Iranica, 66, 166-168.

Büttner, R. (2001). Malus. Hanelt P, Institute of Plant Genetics and Crop Plant Research (Eds) Mansfelds Encyclopedia of Agricultural and Horticultural Crops, 471-482.

Canepa, M. (2010). Distant displays of power: Understanding Cross-Cultural Interaction Among the Elites of Rome, Sasanian Iran, and Sui-Tang China. Ars Orientalis, 38, 121-154. JSTOR. Retrieved from JSTOR.

Castañeda-Álvarez, N. P., Khoury, C. K., Achicanoy, H. A., Bernau, V., Dempewolf, H., Eastwood, R. J., ... Toll, J. (2016). Global conservation priorities for crop wild relatives.

Chen, J., Li, L., Milesi, P., Jansson, G., Berlin, M., Karlsson, B., ... Lascoux, M. (2019). Genomic data provide new insights on the demographic history and the extent of recent material transfers in Norway spruce. Evolutionary Applications, 12(8), 1539-1551. doi: 10.1111/eva.12801 2263.

Cornille, Amandine, Antolín, F., Garcia, E., Vernesi, C., Fietta, A., Brinkkemper, O., ... RoldánRuiz, I. (2019). A Multifaceted Overview of Apple Tree Domestication. Trends in Plant 
71 Cornille, Amandine, Feurtey, A., Gélin, U., Ropars, J., Misvanderbrugge, K., Gladieux, P., \& Giraud, T. (2015). Anthropogenic and natural drivers of gene flow in a temperate wild fruit tree: A basis for conservation and breeding programs in apples. Evolutionary Applications, 8(4), 373-384. doi: 10.1111/eva.12250

Cornille, Amandine, Giraud, T., Smulders, M. J. M., Roldán-Ruiz, I., \& Gladieux, P. (2014). The domestication and evolutionary ecology of apples. Trends in Genetics, 30(2), 57-65. doi:

Cornille, Amandine, Gladieux, P., \& Giraud, T. (2013a). Crop-to-wild gene flow and spatial genetic structure in the closest wild relatives of the cultivated apple. Evolutionary Applications, 6(5), 737-748. doi: 10.1111/eva.12059

Cornille, Amandine, Gladieux, P., \& Giraud, T. (2013b). Crop-to-wild gene flow and spatial genetic structure in the closest wild relatives of the cultivated apple. Evolutionary Applications, 6(5), 737-748. doi: 10.1111/eva.12059 Genetics, 8(5). doi: 10.1371/journal.pgen.1002703

Decroocq, S., Cornille, A., Tricon, D., Babayeva, S., Chague, A., Eyquard, J. P., ... Decroocq, V. ... Giraud, T. (2012). New insight into the history of domesticated apple: Secondary contribution of the European wild apple to the genome of cultivated varieties. PLoS (2016). New insights into the history of domesticated and wild apricots and its contribution to Plum pox virus resistance. Molecular Ecology, 25(19), 4712-4729. doi: (2015). Olive domestication and diversification in the Mediterranean Basin. New Phytologist, 206(1), 436-447. doi: 10.1111/nph.13181 
95 Duan, N., Bai, Y., Sun, H., Wang, N., Ma, Y., Li, M., ... Chen, X. (2017). Genome resequencing reveals the history of apple and supports a two-stage model for fruit

Earl, D. A. (2012). STRUCTURE HARVESTER: a website and program for visualizing STRUCTURE output and implementing the Evanno method. Conservation Genetics Resources, 4(2), 359-361.

101 Estoup, A. A., Raynal, L., Verdu, P., \& Marin, J.-M. (2018). Model choice using Approximate Bayesian Computation and Random Forests: Analyses based on model grouping to make inferences about the genetic history of Pygmy human populations. Journal de La Societe

Evanno, G., Regnaut, S., \& Goudet, J. (2005). Detecting the number of clusters of individuals using the software STRUCTURE: a simulation study. Molecular Ecology, 14(8), 26112620.

108 Excoffier, L., \& Foll, M. (2011). fastsimcoal: A continuous-time coalescent simulator of genomic diversity under arbitrarily complex evolutionary scenarios. Bioinformatics, 27(9), 13321334. doi: 10.1093/bioinformatics/btr124

111 Excoffier, L., Foll, M., \& Petit, R. J. (2009). Genetic Consequences of Range Expansions. Annual Review of Ecology, Evolution, and Systematics, 40(1), 481-501. doi: 10.1146/annurev.ecolsys.39.110707.173414

114 Excoffier, L., \& Lischer, H. E. L. (2010). Arlequin suite ver 3.5: A new series of programs to perform population genetics analyses under Linux and Windows. Molecular Ecology Resources, 10(3), 564-567. doi: 10.1111/j.1755-0998.2010.02847.x

118 flow and its fitness consequences for a wild fruit tree: Towards a comprehensive 

188. PMC (PMC5253423). doi: 10.1111/eva.12441

121 Feurtey, A., Cornille, A., Shykoff, J. A., Snirc, A., \& Giraud, T. (2017b). Crop $\square$ to $\square$ wild gene flow and its fitness consequences for a wild fruit tree: Towards a comprehensive conservation strategy of the wild apple in Europe. Evolutionary Applications, 10(2), 180-

Fieldings, A. H., \& Bell, J. F. (1997). A review of methods for the assessment of prediction errors in conservation presence/absence models. Environmental Conservation, 24, 38-49.

Fischer, A., \& Schmidt, M. (1938). Wilde Kern-und Steinobstarten, ihre Heimat und ihre Bedeutung für die Entstehung der Kultursorten und die Züchtung. Der Züchter, 10(6), $157-167$.

130 Flowers, J. M., Hazzouri, K. M., Gros-Balthazard, M., Mo, Z., Koutroumpa, K., Perrakis, A., ... Purugganan, M. D. (2019). Cross-species hybridization and the origin of North African

134 Forsline, P. L., Aldwinckle, H. S., Dickson, E. E., Luby, J. J., \& Hokanson, S. C. (2003). Of Wild Apples of Central Asia (Vol. 29).

136 Fuller, D. Q. (2018). Long and attenuated: Comparative trends in the domestication of tree fruits. Vegetation History and Archaeobotany, 27(1), 165-176. doi: 10.1007/s00334-017-0659-2

138 Gabrielian, E. T., \& Zohary, D. (2004). Wild relatives of food crops native to Armenia and Nakhichevan. Flora Mediterranea, 14, 5-80.

140 Gaut, B. S., Díez, C. M., \& Morrell, P. L. (2015). Genomics and the Contrasting Dynamics of 141 Annual and Perennial Domestication. Trends in Genetics, 31(12), 709-719. doi: 
143 Gharghani, A., Zamani, Z., Talaie, A., Fattahi, R., Hajnajari, H., Oraguzie, N. C., ... Gardiner, S. E. (2010). The Role of Iran (Persia) in Apple (Malus $\times$ domestica Borkh.) Domestication,

146 Gharghani, Ali, Zamani, Z., Talaie, A., Oraguzie, N. C., Fatahi, R., Hajnajari, H., ... Gardiner, S. E. (2009). Genetic identity and relationships of Iranian apple (Malus× domestica Borkh.) Evolution and Migration via the Silk Trade Route. Acta Horticulturae, (859), 229-236.

151 Giesecke, T., Brewer, S., Finsinger, W., Leydet, M., \& Bradshaw, R. H. W. (2017). Patterns and dynamics of European vegetation change over the last 15,000 years. Journal of Biogeography, 44(7), 1441-1456. doi: 10.1111/jbi.12974

Gros-Balthazard, M., \& Flowers, J. M. (2021). A Brief History of the Origin of Domesticated Date Palms. In J. M. Al-Khayri, S. M. Jain, \& D. V. Johnson (Eds.), The Date Palm Genome, Vol. 1: Phylogeny, Biodiversity and Mapping (pp. 55-74). Cham: Springer International Publishing. doi: 10.1007/978-3-030-73746-7_3

161 Hardy, O. J., \& Vekemans, X. (2002). SPAGeDi: A versatile computer program to analyse spatial genetic structure at the individual or population levels. Molecular Ecology Notes, 2(4),

164 Hewitt, G. M. (1990). Divergence and speciation as viewed from an insect hybrid zone. Canadian Journal of Zoology, 68(8), 1701-1715. doi: 10.1139/z90-251 
166

167

168

169

170

171

172

173

174

175

176

177

178

180

Hewitt, G. M. (2004). Genetic consequences of climatic oscillations in the Quaternary. Philosophical Transactions of the Royal Society of London. Series B: Biological Sciences, 359(1442), 183-195. doi: 10.1098/rstb.2003.1388

Hewitt, Godfrey M. (1996). Some genetic consequences of ice ages, and their role in divergence and speciation. Biological Journal of the Linnean Society, 58(3), 247-276. doi: 10.1006/bijl.1996.0035

Höfer, M., Flachowsky, H., Hanke, M.-V., Semënov, V., Šlâvas, A., Bandurko, I., ... Alexanian, S. (2013). Assessment of phenotypic variation of Malus orientalis in the North Caucasus region. Genetic Resources and Crop Evolution, 60(4), 1463-1477. doi: 10.1007/s10722012-9935-2

Huson, D. H. (1998). SplitsTree: Analyzing and visualizing evolutionary data. Bioinformatics (Oxford, England), 14(1), 68-73.

Huson, D. H., \& Scornavacca, C. (2012). Dendroscope 3: An interactive tool for rooted phylogenetic trees and networks. Systematic Biology, 61(6), 1061-1067.

Jezkova, T., Olah-Hemmings, V., \& Riddle, B. R. (2011). Niche shifting in response to warming climate after the last glacial maximum: Inference from genetic data and niche assessments in the chisel-toothed kangaroo rat (Dipodomys microps). Global Change Biology, 17(11), 3486-3502. doi: 10.1111/j.1365-2486.2011.02508.x

Jombart, T., \& Ahmed, I. (2011). adegenet 1.3-1: New tools for the analysis of genome-wide SNP data. Bioinformatics, 27(21), 3070-3071. doi: 10.1093/bioinformatics/btr521

Langenfeld, W. T. (1991). Apple trees. Morphological Evolution, Phylogeny, Geography and Systematics. Riga (Zinatne), 232. 
188 Lascoux, M., Palmé, A. E., Cheddadi, R., \& Latta, R. G. (2004). Impact of Ice Ages on the genetic structure of trees and shrubs. Philosophical Transactions of the Royal Society B: Biological Sciences, 359(1442), 197-207. doi: 10.1098/rstb.2003.1390

191 Leroy, B., Bellard, C., Dubos, N., Colliot, A., Vasseur, M., Courtial, C., ... Ysnel, F. (2014). Forecasted climate and land use changes, and protected areas: The contrasting case of spiders. Diversity and Distributions, 20(6), 686-697. doi: 10.1111/ddi.12191

194 Liang, Z., Duan, S., Sheng, J., Zhu, S., Ni, X., Shao, J., ... Dong, Y. (2019). Whole-genome resequencing of 472 Vitis accessions for grapevine diversity and demographic history analyses. Nature Communications, 10(1), 1190. doi: 10.1038/s41467-019-09135-8

197 Liu, S., Cornille, A., Decroocq, S., Tricon, D., Chague, A., Eyquard, J., ... Decroocq, V. (2019). The complex evolutionary history of apricots: Species divergence, gene flow and multiple

Loiselle, B. A., Sork, V. L., Nason, J., \& Graham, C. (1995). Spatial genetic structure of a tropical understory shrub, Psychotria officinalis (Rubiaceae). American Journal of

Mabry, M. E., Rowan, T. N., Pires, J. C., \& Decker, J. E. (2021). Feralization: Confronting the Complexity of Domestication and Evolution. Trends in Genetics, 37(4), 302-305. doi: 10.1016/j.tig.2021.01.005

Matsuoka, Y., Vigouroux, Y., Goodman, M. M., Sanchez G, J., Buckler, E., \& Doebley, J. (2002). A single domestication for maize shown by multilocus microsatellite genotyping. PNAS, 99(9), 6080-6084. doi: 10.1073/pnas.052125199 An historical review and quantitative analysis of 203 global food crops. New Phytologist, 196(1), 29-48. doi: 10.1111/j.1469-8137.2012.04253.x 
212 Monserud, R. A., \& Leemans, R. (1992). Comparing global vegetation maps with the Kappa statistic. Ecological Modelling, 62(4), 275-293.

214 Myles, S., Boyko, A. R., Owens, C. L., Brown, P. J., Grassi, F., Aradhya, M. K., ... Buckler, E. S. (2011). Genetic structure and domestication history of the grape. Proceedings of the National Academy of Sciences of the United States of America, 108(9), 3530-3535. doi: 10.1073/pnas. 1009363108

218 Nakhutsrishvili, G., Zazanashvili, N., Batsatsashvili, K., \& Montalvo, CS. (2015). Colchic and Hyrcanian forests of the Caucasus: Similarities, differences and conservation status. Flora Mediterranea, 25, 185-192.

Nei, M. (1987). Molecular Evolutionary Genetics. Columbia University Press. Retrieved from https://books.google.es/books?id=UhRSsLkjxDgC

Oddou-Muratorio, S., \& Klein, E. K. (2008). Comparing direct vs. Indirect estimates of gene flow within a population of a scattered tree species. Molecular Ecology, 17(11), 2743Hanke, M.-V. (2017). To what extent do wild apples in Kazakhstan retain their genetic

Parvizi, E., Keikhosravi, A., Naderloo, R., Solhjouy-Fard, S., Sheibak, F., \& Schubart, C. D. (2019). Phylogeography of Potamon ibericum (Brachyura: Potamidae) identifies Quaternary glacial refugia within the Caucasus biodiversity hot spot. Ecology and

233 Patocchi, A., Fernàndez-Fernàndez, F., Evans, K., Gobbin, D., Rezzonico, F., Boudichevskaia, A., ... van de Weg, W. (2009). Development and test of 21 multiplex PCRs composed of 
Patocchi, A., Frei, A., Frey, J. E., \& Kellerhals, M. (2009). Towards improvement of marker assisted selection of apple scab resistant cultivars: Venturia inaequalis virulence surveys and standardization of molecular marker alleles associated with resistance genes. Molecular Breeding, 24(4), 337-347. doi: 10.1007/s11032-009-9295-6

Petit, R. J., Bialozyt, R., Garnier-Géré, P., \& Hampe, A. (2004). Ecology and genetics of tree invasions: From recent introductions to Quaternary migrations. Forest Ecology and Management, 197(1-3), 117-137. doi: 10.1016/j.foreco.2004.05.009

Petit, R. J., \& Hampe, A. (2006). Some Evolutionary Consequences of Being a Tree. Annual Review of Ecology, Evolution, and Systematics, 37(1), 187-214. doi: 10.1146/annurev.ecolsys.37.091305.110215

Pritchard, J. K., Stephens, M., \& Donnelly, P. (2000). Inference of population structure using multilocus genotype data. Genetics, 155(2), 945-959.

Pudlo, P., Marin, J.-M., Estoup, A., Cornuet, J.-M., Gautier, M., \& Robert, C. P. (2016). Reliable ABC model choice via random forests. Bioinformatics, 32(6), 859-866. doi: 10.1093/bioinformatics/btv684

Puechmaille, S. J. (2016). The program structure does not reliably recover the correct population structure when sampling is uneven: Subsampling and new estimators alleviate the problem. Molecular Ecology Resources, 16(3), 608-627. doi: 10.1111/1755-0998.12512

Qiu, J., Wang, L., Liu, M., Shen, Q., \& Tang, J. (2011). An efficient and simple protocol for a PdCl2-ligandless and additive-free Suzuki coupling reaction of aryl bromides. Tetrahedron Letters, 52(48), 6489-6491. doi: 10.1016/j.tetlet.2011.09.115

Raymond, M., \& Rousset, F. (1995). An exact test for population differentiation. Evolution, 49(6), 1280-1283. 
Raynal, L., Marin, J.-M., Pudlo, P., Ribatet, M., Robert, C. P., \& Estoup, A. (2019). ABC random forests for Bayesian parameter inference. Bioinformatics, 35(10), 1720-1728. doi: 10.1093/bioinformatics/bty867

Rechinger, K. H. (1964). Flora Iranica, Akademische Druck-und Verlagsanstalt Graz. University of Tehran, Iran, 549.

Rousset, F. (2008). genepop'007: A complete re $\square$ implementation of the genepop software for Windows and Linux. Molecular Ecology Resources, 8(1), 103-106.

Schmitt, T. (2007). Molecular biogeography of Europe: Pleistocene cycles and postglacial trends. Frontiers in Zoology, 4, 1-13. doi: 10.1186/1742-9994-4-11

Soofi, M., Ghoddousi, A., Zeppenfeld, T., Shokri, S., Soufi, M., Jafari, A., ... Waltert, M. (2018). Livestock grazing in protected areas and its effects on large mammals in the Hyrcanian forest, Iran. Biological Conservation, 217, 377-382. doi: 10.1016/j.biocon.2017.11.020

Spengler, R.N. (2019). Fruit from the Sands: The Silk Road Origins of the Foods We Eat. https://books.google.fr/books?id=fr6SDwAAQBAJ

Spengler, Robert N., Chang, C., \& Tourtellotte, P. A. (2013). Agricultural production in the Central Asian mountains: Tuzusai, Kazakhstan (410-150 b.c.). Journal of Field Archaeology, 38(1), 68-85. doi: 10.1179/0093469012Z.00000000037

Spengler, Robert Nicholas. (2019). Origins of the Apple: The Role of Megafaunal Mutualism in 2504. 
Tardío, J., Arnal, A., \& Lázaro, A. (2020). Ethnobotany of the crab apple tree (Malus sylvestris (L.) Mill., Rosaceae) in Spain. Genetic Resources and Crop Evolution. doi: 10.1007/s10722-020-01026-y

Teixeira, J. C., \& Huber, C. D. (2021). The inflated significance of neutral genetic diversity in conservation genetics. Proceedings of the National Academy of Sciences, 118(10), e2015096118. doi: 10.1073/pnas.2015096118

Thuiller, W., Georges, D., Engler, R., \& Breiner, F. (2016). Biomod2: Ensemble platform for species distribution modeling. $R$ package version 3.3-7.

Tian, F., Li, B., Ji, B., Zhang, G., \& Luo, Y. (2009). Identification and structure-activity relationship of gallotannins separated from Galla chinensis. LWT - Food Science and Technology, 42(7), 1289-1295. doi: 10.1016/j.lwt.2009.03.004

Vavilov, N. I. (1926). Studies on the origin of cultivated plants. Trudy Byuro. Prikl. Bot., 16, $139-245$.

Vavilov, N. I. (1992). Origin and geography of cultivated plants. Cambridge: Cambridge University Press. CABDirect.

Vekemans, X., \& Hardy, O. J. (2004a). New insights from fine-scale spatial genetic structure analyses in plant populations. Molecular Ecology, 13(4), 921-935. doi: 10.1046/j.1365294X.2004.02076.x

Vekemans, X., \& Hardy, O. J. (2004b). New insights from fine-scale spatial genetic structure analyses in plant populations. Molecular Ecology, 13(4), 921-935.

Volk, G. M., \& Cornille, A. (2019). Genetic Diversity and Domestication History in Pyrus. In The Pear Genome (pp. 51-62). Springer.

Volk, G. M., Richards, C. M., Reilley, A. A., Henk, A. D., Reeves, P. A., Forsline, P. L., \& Aldwinckle, H. S. (2008). Genetic diversity and disease resistance of wild Malus 
orientalis from Turkey and Southern Russia. Journal of the American Society for Horticultural Science, 133(3), 383-389.

Vouillamoz, J. F., McGovern, P. E., Ergul, A., Söylemezoğlu, G., Tevzadze, G., Meredith, C. P., cultivars from Transcaucasia and Anatolia. Plant Genetic Resources, 4(2), 144-158. doi:

Wegmann, D., Leuenberger, C., Neuenschwander, S., \& Excoffier, L. (2010). ABCtoolbox: A versatile toolkit for approximate Bayesian computations. BMC Bioinformatics, 11(1), 116. doi: 10.1186/1471-2105-11-116

Wu, J., Wang, Y., Xu, J., Korban, S. S., Fei, Z., Tao, S., ... Zhang, S. (2018). Diversification and

Yousefzadeh, H., Hosseinzadeh Colagar, A., Tabari, M., Sattarian, A., \& Assadi, M. (2012). Utility of ITS region sequence and structure for molecular identification of Tilia species independent domestication of Asian and European pears. Genome Biology, 19(1), 77. doi:

Zazanashvili, N., Sanadiradze, G., Garforth, M., Bitsadze, M., Manvelyan, K., Askerov, E., ... Devranoğlu Tavsel, S. (2020). Ecoregional Conservation Plan (ECP) For The Caucasus 2020 Edition. WWF, KfW, Tbilisi. archaea and bacteria to microbial ammonia oxidation differ under different conditions during agricultural waste composting. Bioresource Technology, 102(19), 9026-9032. doi: 10.1016/j.biortech.2011.07.076 
330 Zhang, H., Mittal, N., Leamy, L. J., Barazani, O., \& Song, B. H. (2017). Back into the wildApply untapped genetic diversity of wild relatives for crop improvement. Evolutionary Applications, 10(1), 5-24. doi: 10.1111/eva.12434

333 Zhang, H.-X., Li, H.-Y., \& Li, Y.-X. (2018). Identifying evolutionarily significant units for

334 conservation of the endangered Malus sieversii using genome-wide RADseq data. Nordic 


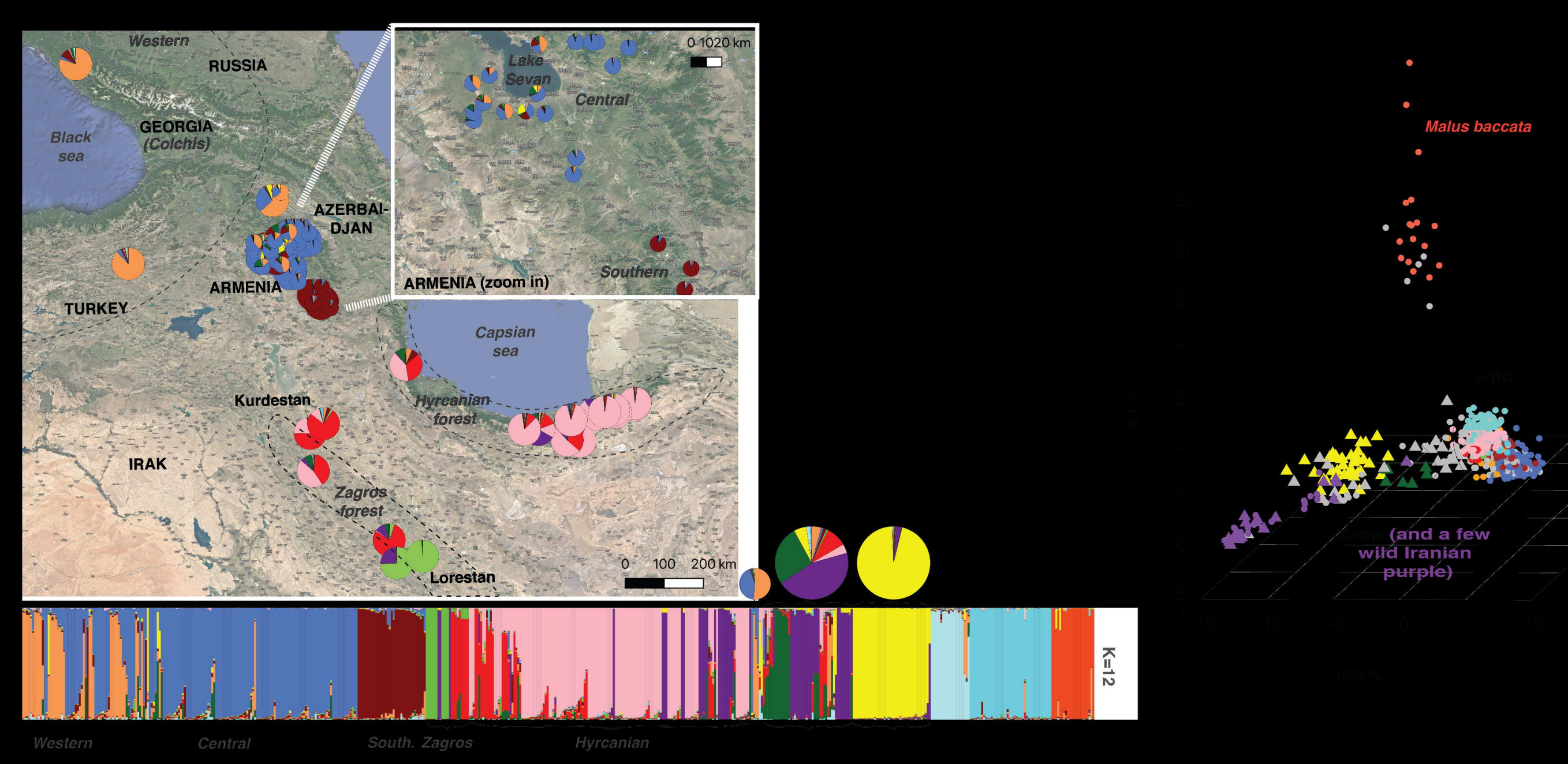

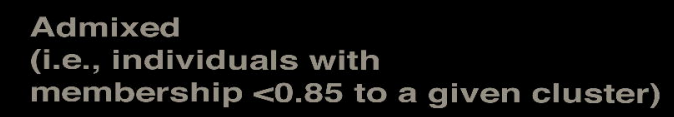

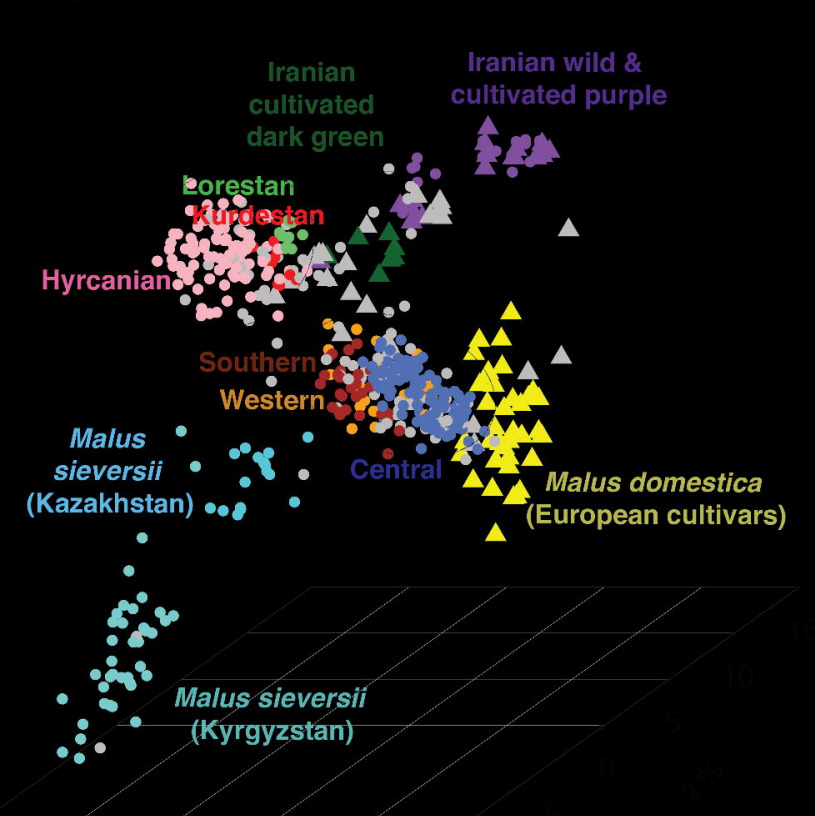



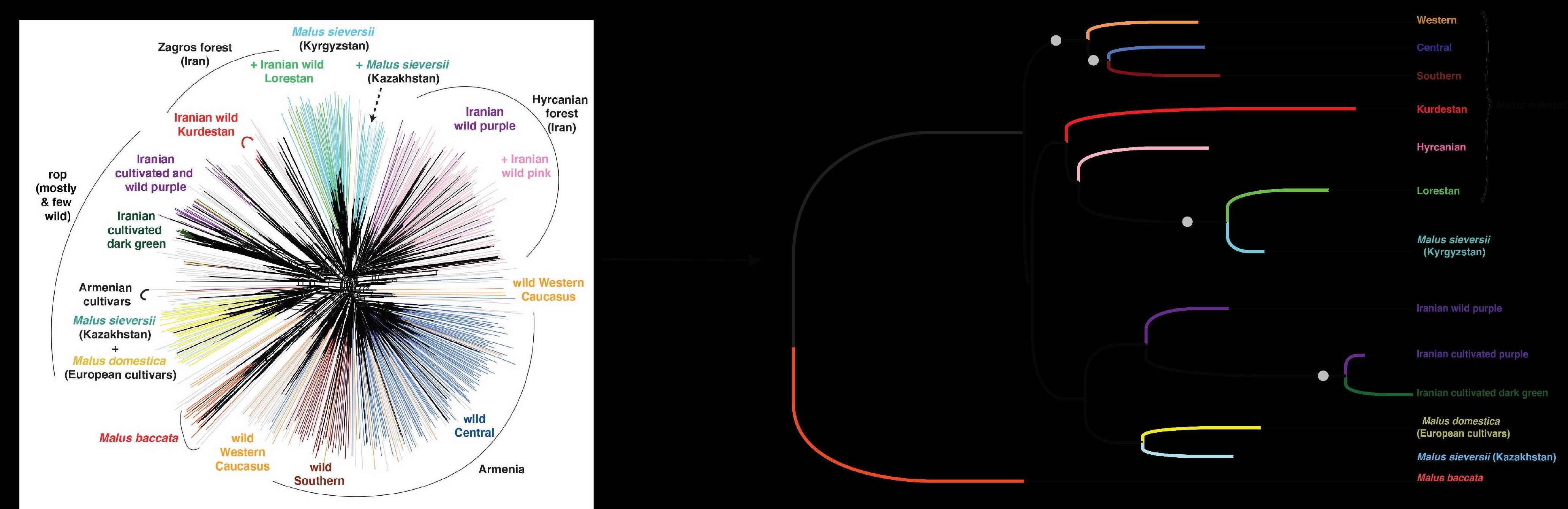

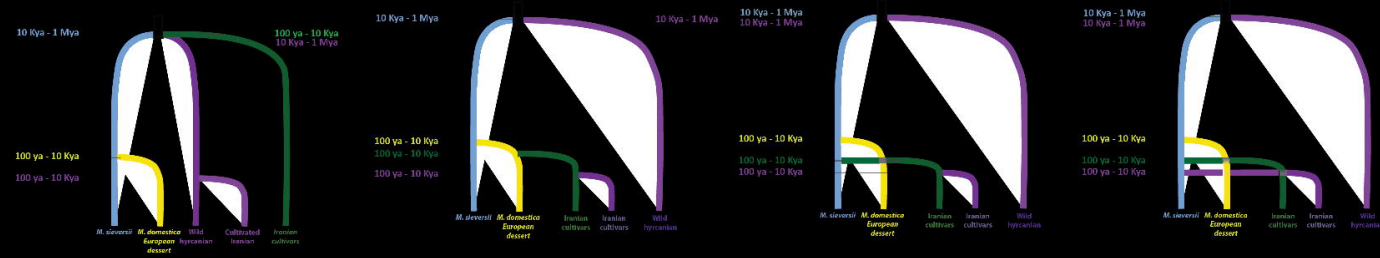
Irenian cultivars wild purple iranian

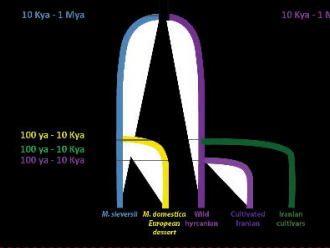

Greup comparison:
Number of votes (and \%)
Posterior probability:
Prior error rate:

Group comparison (only 'WP-after scenarios):

\section{Best scenario:}

Number of votes (and \%):

Posterior probability:

Prior error rate:

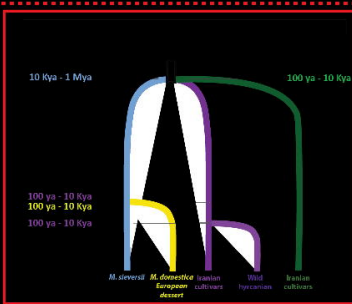

Mreforrestice

Iranian gresn Mi sieversii

M. sicversii

100 ya -10 kye 100 ya- 10 ma

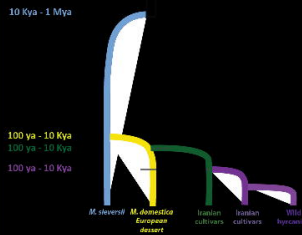

$100 \mathrm{Ya}-10 \mathrm{Kya}$ $100 \mathrm{Ya}-10 \mathrm{KYa}$
$100 \mathrm{Ya}-10 \mathrm{Kya}$

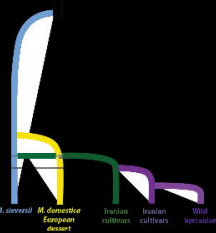



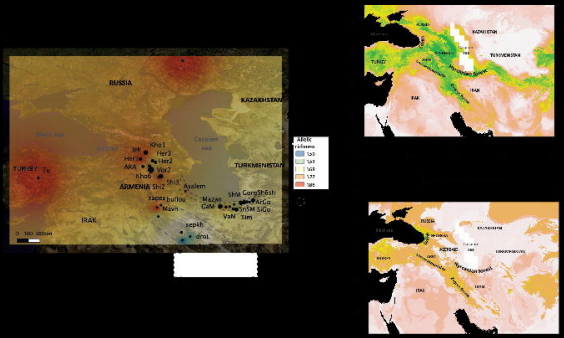